\title{
Categories and Paradigms. On Underspecification in Russian Declension
}

\author{
Bernd Wiese*
}

\section{Introduction}

In morphological systems of the agglutinative type we sometimes encounter a nearly perfect one-to-one relation between form and function. Turkish inflectional morphology is, of course, the standard textbook example. Things seem to be quite different in systems of the flexive type. Declension in Contemporary Standard Russian (henceforth Russian, for short) may be cited as a typical example: We find, among other things, cumulative markers, "synonymous" endings (e.g., dative singular noun forms in $-i,-e$, or $-u$ ), and "homonymous" endings (e.g., $-i$, genitive, dative, and prepositional singular). True, some endings are more of an agglutinative nature, being bound to a specific case-number combination and applying across declensions, e.g., -am (dative plural, all nouns); and some cross the boundaries of word classes, e.g., - $o$, which serves as the nominative/accusative singular ending of neuter forms of pronouns (and adjectives) and as the nominative/accusative singular ending of (most) neuter nouns as well. Still, many observers have been struck by the impression that what we face here are rather uneconomic or even, so to speak, unnatural structures. But perhaps flexive systems are not as complicated as they seem. What seems to be uneconomic complexity may be, at least partially, an artifact of uneconomic descriptions. ${ }^{1}$

\footnotetext{
*An earlier version of this paper was presented at the Workshop on Inflectional Paradigms, held at the Institut für Deutsche Sprache (IDS), Mannheim, May 23-24, 2003. I should like to thank the participants of the workshop and the editors of this volume for helpful comments, Gereon Müller in particular, whose analysis of Russian noun declension (Müller (this volume)) has been highly stimulating. Special thanks to Matthew Baerman for making available Baerman (2003). The study presented here is part of an inquiry collateral to the IDS project Grammatik des Deutschen im europäischen Vergleich (principal investigator Gisela Zifonun).

${ }^{1}$ See Lyons (1968, 290-293) and Plank (1991) for contrastive presentations of Turkish and Latin; cf. Matthews (1991, 179) on Russian and Plank (1999) on flexion-agglutination splits in various languages, including Russian.
} 
Taking traditional paradigmatic tables as a point of departure we note that, in Russian, the number of paradigmatic cells is rather large compared to the number of morphological markers, especially endings, which serve to distinguish the forms that fill the cells. ${ }^{2}$ Paradigms serve to list the various forms and to relate forms to "bundles of categories" so as to provide for "categorizations". But unfortunately, tradition has little to offer when we ask for the factors, if any, that control the distribution of markers over forms or cells in paradigms. In the present essay, I argue that distribution is not random but reflects a structured roster of declensional endings that will be detailed below. As a result, a tangled web of many-to-many form-function relations reduces to a rather well organized common structure that underlies declensional paradigms and is formed by a set of about twenty ending-categorization pairs (more precisely, pairs of types of endings and sets of categories). Systematic syncretisms are resolved and endings are given characterizations that account for their functional unity as well as for their diversity of application.

Regarding the inventory of Russian declensional endings and their morphophonological analyses, I shall take my lead from Jakobson (1958). Considerations of markedness and iconicity will be integrated; however, I shall not adopt Jakobson's feature-based analysis of Russian cases (first developed in Jakobson (1936)). In fact, the present approach is not feature-based but classificatory, couched in a "declarative" surface-morphological approach, and as such relates to Trubetzkoy (1934).

Often, Russian is assumed to show two basic types of declensions: adjectival and nominal. In reference grammars, pronouns tend to come last and are said to show a "mixed" declension. However, pronouns definitely occupy a central position in declensional systems. Starting with pronouns proves to be profitable as we aim at a more coherent view of Russian declension.

Section 2 presents an analysis of Russian pronominal declension based on a conception of underspecified paradigms that will be outlined as discussion proceeds. ${ }^{3}$ The paradigm of the demonstrative pronoun ЀTOT ('this') serves

\footnotetext{
${ }^{2}$ Assuming (at least) six cases, two numbers, three genders, three declensions of nouns, plus paradigms for adjectives and pronouns, even disregarding animacy we get somewhere between 100 and 200 paradigmatic cells, depending on different choices of detail in presentation. The number of endings is a small fraction of this value.

${ }^{3}$ Cf. Wiese (1991/1999); for some background discussion, see Wiese (1996). Compare also the conceptions of (underspecified) paradigms put forward in Williams (1981; 1994) and Blevins $(1995 ; 2003)$. For relevant treatments of syncretism with special reference to Russian, see Comrie $(1986 ; 1991)$ and Corbett \& Fraser (1993). For a balanced overview of feature-
} 
for exemplification; with minor emendations, the analysis to be proposed applies also to adjectives. In section 3, the conception developed is extended to nouns; special properties of noun declension are taken care of by a limited set of additions to a core system instantiated most transparently by pronouns. ${ }^{4}$ Section 4 adds a short discussion of types of syncretisms, focusing on the Russian genitive-accusative. Section 5 offers some concluding remarks.

\section{Pronouns and Adjectives}

\subsection{Preliminaries: Terms and Notions}

The following analysis will be framed in a traditional word-and-paradigm approach, which will be modified, however, so as to integrate the notion of underspecification and the principle of specificity ("Pānini's rule"). ${ }^{5}$ Generally speaking, paradigms must provide categorizations for word forms, meaning that they serve to specify morphosyntactic properties of forms by locating these forms in a complex system of classifications. As for Russian declension, relevant classifications include case and number, which are classifications of word forms, and gender, which is a classification of lexemes (for nouns) and a classification of word forms (for pronouns and adjectives). ${ }^{6}$ For example, the Russian pronominal form ètomu is a dative singular masculine or neuter form of the lexeme ЀтOT, which is a demonstrative pronoun. Categories may be regarded as sets as illustrated in (1) using dative forms - both singular and plural - of two pronouns and one adjective (viz., ЀтоT ('this'), тот ('that'), NOVIJ ('new')); very informally, dat is the set of dative forms.

based treatments of case, see Blake (1994) and for an innovative analysis of Russian noun declension, Müller (this volume). For an overview of a "geometric" approach to paradigms and syncretism, including application to Russian, see Johnston (1997), based on McCreight \& Chvany (1991).

${ }^{4}$ The following analysis is restricted to the major nominal, pronominal, and adjectival paradigms of the standard language as given in reference grammars (cf. note 6, infra). Not included are treatments of word stress and stem alternations, particularities of numerals and proper names as well as minor subregularities and irregular paradigms.

${ }^{5}$ Also called the "Elsewhere-principle" (Kiparsky (1973)), here applied to paradigms; cf. Andrews (1982; 1990). Cf. also Wunderlich (1996) and references in note 3.

${ }^{6}$ Useful surveys of Russian morphology include Isačenko (1962), Garde (1980), and Mulisch (1988); cf. also Unbegaun (1957), Wade (1992), Timberlake (2004), and other reference grammars, as well as Cubberley (2002). For noun declension in particular, see Trager (1953), Stankiewicz (1968), Kortlandt (1974), and Halle (1994). 
(1) dat $=\{$ ètomu, ètoj, ètim, tomu, toj, tem, novomu, novoj, novim, ... $\}$

Actually, case classification (in Russian) may be taken to constitute not a single classification but a (hierarchical) system of classifications, which must provide at least six cases (classes of word-forms), dative being one of them. In a preliminary manner, subject to revision below, this system may be presented by means of a classification tree as in (2); abbreviations used are nom (nominative), acc (accusative), pre (prepositional), dat (dative), gen (genitive), and ins (instrumental).

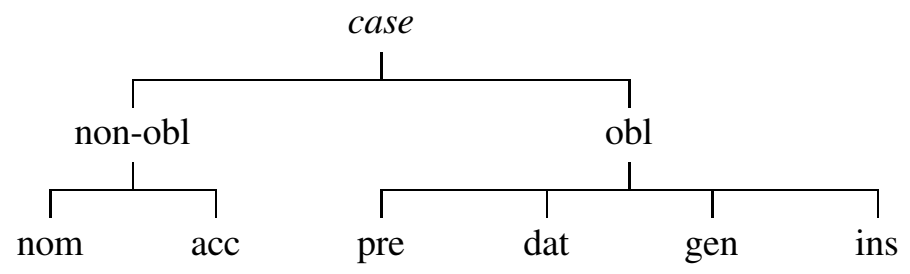

A first case classification provides a division of the set of case forms into two major categories: non-oblique (or direct) and oblique. ${ }^{7}$ Both of these categories are subcategorized as shown in (2). The end-points or terminal categories of the system are the traditional case categories. ${ }^{8}$ As categories are taken to be sets, subordinate categories are subsets of superordinate categories; e.g., dative is a subset of oblique (dat $\subset$ obl), while oblique is the union of prepositional, dative, genitive, and instrumental (obl $=$ pre $\cup$ dat $\cup$ gen $\cup$ ins). Cases that are subsets of oblique and non-oblique will be referred to as oblique cases and non-oblique cases, respectively; e.g., dative is an oblique case.

\footnotetext{
${ }^{7}$ The primary division into non-oblique (direct) vs. oblique is taken from Trubetzkoy (1934). This division is orthogonal to Jakobson's feature system of 1936, but has been added up to (though not integrated into) that system in Jakobson (1958), undoubtedly because of its immense descriptive value. It has been kept in subsequent studies, including Stankiewicz (1968, 22, passim), which provides a detailed analysis of Russian noun declension, and Schenker (1964), on Polish; it has been widely adopted in different frameworks (e.g., in Greenberg (1966), Bierwisch (1967)). (Terminology differs, of course; Blake (1994) adopts core cases vs. peripheral cases.) This use of the term "oblique" must not be confused with the more traditional one that contrasts nominative and oblique.

${ }^{8}$ Traditional linguistics applies the term "category" to entities like case - in terms of the present approach, (systems of) classifications - and to entities like nominative - in terms of the present approach, sets of forms or lexemes. In the following, "category" will be used in the second sense only.
} 
Given the hierarchical systems in (2) and in (3), below, we may avail ourselves of non-terminal categories such as oblique as means for grammatical categorization. It is this use made of non-terminal categories that crucially distinguishes the present approach from those of traditional grammar. As will be seen, a major impact of making available superordinate (non-terminal) categories is to allow a natural treatment of syncretisms. For instance, a form like ètoj (of ЀтOT), which serves in the prepositional, the instrumental, the genitive, and the dative, may best be categorized as a plain oblique form (i.e., ètoj $\in$ obl).

Classification trees for gender and number are given in (3); abbreviations to be used below are masc (masculine), fem (feminine), neut (neuter), sg (singular), pl (plural).

(3)

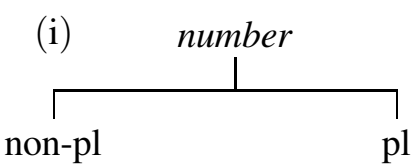

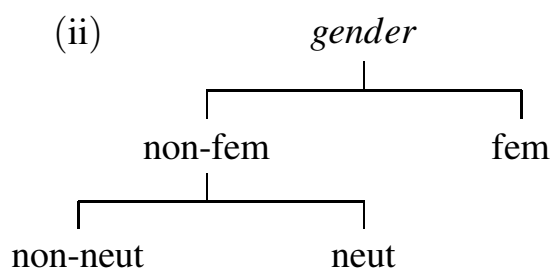

There is a first gender classification non-fem vs. fem; non-fem splits into neut and non-neut (which is but an alternative name for masc; i.e., non-neut $=$ masc). ${ }^{9}$ The category names used in (2) and (3) are chosen so as to reflect relations of markedness, but alternative names such as direct (for non-oblique) or masc may be used freely for convenience. There is only one number classification (without subclassifications); non-pl $=\mathrm{sg}$, of course.

Given these classification systems, word forms may be assigned to bundles of categories; e.g., the form ètoju (of Ётот) is related to the categories instrumental, singular, and feminine. Such a bundle of categories - that is, a set of categories - will be called a categorization, as indicated in (4ii).

(i) a word form:

ètoju

(ii) a categorization:

$\{$ ins, sg, fem $\}$

(iii) a grammatical word:

$\langle\grave{e} t o j u,\{$ ins, sg, fem $\}\rangle$

Combining a form and its categorization, we get a "grammatical word", where the word form is contained in every category in the categorization; applied to the example at hand, ètoju $\in \cap\{$ ins, sg, fem $\}$. Paradigms can, then,

\footnotetext{
${ }^{9}$ Trubetzkoy (1934), cf. also Jakobson (1960); for (dissenting) discussion, Stankiewicz $(1968,19)$.
} 
be regarded as sets of grammatical words. For example, the grammatical word given in (4iii) is assumed to be an element of the paradigm of Еेтот; more formally, $\langle\grave{e} t o j u,\{$ ins, sg, fem $\}\rangle \in$ ÈTOT $^{\mathrm{P}}$ (with superscript "P" for "paradigm"). ${ }^{10}$

As will be shown, some progress towards a better understanding of formfunction relations may be made if non-terminal categories (e.g., obl or nonfem) are allowed in paradigmatic categorizations. The plain oblique form ètoj referred to above provides an example given its categorization as $\{\mathrm{obl}, \mathrm{sg}$, fem . Paradigms that contain grammatical words whose categorizations include non-terminal categories will be called underspecified paradigms.

A further classification of Russian pronominal and adjectival forms, traditionally known as subgender, pertains to animacy (animation) and provides two categories: animate and inanimate (anim and inanim, for short). In addition, a corresponding syntactic classification of noun lexemes has to be assumed even if the semantic foundation of this classification is still transparent to a large degree. ${ }^{11}$

Categories provided by the classification systems discussed so far are termed functional categories - as opposed to form categories, which are determined in terms of formal (morphological, expression-related) properties (cf. 2.5). ${ }^{12}$

\subsection{Gender Syncretisms}

Table 1 presents the forms of the most frequent Russian demonstrative pronoun Ѐтот ('this'). The arrangement of the table is fairly traditional, but some moves have been made to throw into relief the structure of gender syncretisms. ${ }^{13}$

Names of superordinate categories have been inserted into the headers of

\footnotetext{
${ }^{10}$ This conception of paradigms is taken from Lieb (1980); for Lieb's explication of the traditional notion of paradigm, see further Lieb (1980; 1992; 2003). Cf. also Zwicky (1990), Stump (2001; 2002), and Blevins (2003). Non-simple word forms may be allowed as forms of paradigms (Williams $(1994,23)$ ).

${ }^{11}$ For discussion, see Corbett (1980).

${ }^{12}$ On functional categories and form categories, see Comrie (1991), Lieb (2003, sec. 2); cf. also Wiese (1996).

${ }^{13}$ Cf. Halle (1994, 44). The order of cases follows Chvany (1982). As usual, word-forms are given in transliterated standard orthography throughout; names of lexemes or paradigms are written in small capitals. However, morphophonemic transcription will be used in representations of endings below.
} 
Table 1: Forms of pronoun ÈTOT

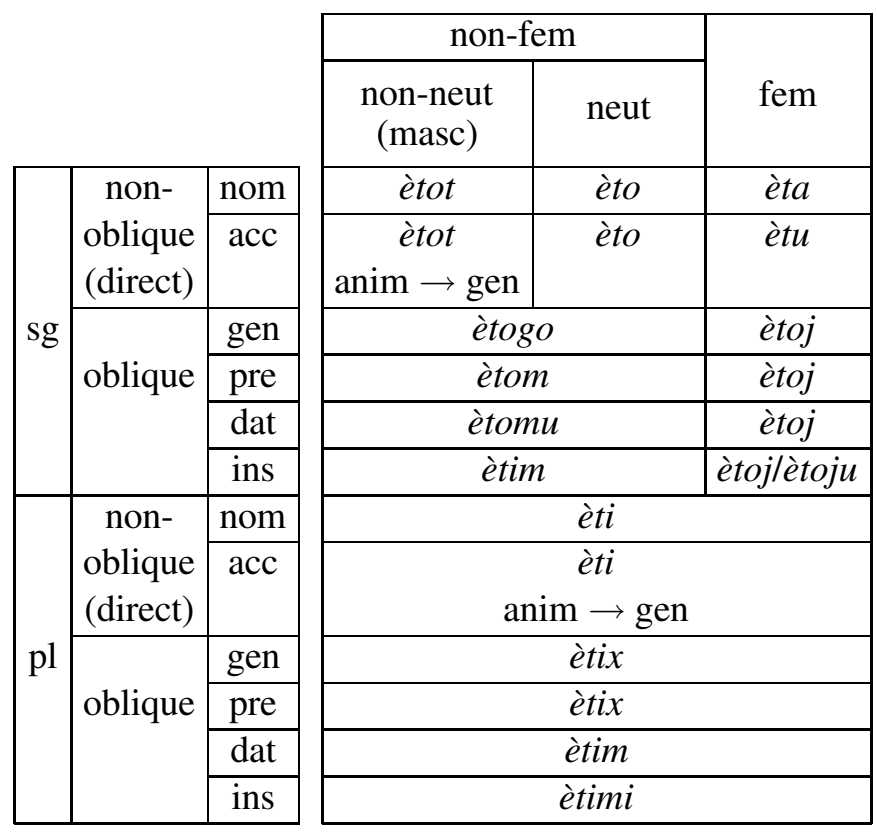

columns and rows. Reference to superordinate categories helps to identify domains of syncretism: There is no gender distinction in the plural, oblique cases of the singular show the superordinate gender distinction only (i.e., fem vs. non-fem), and it is only non-oblique cases of the singular that add the neuter vs. non-neuter distinction. Inspection of Table 1 supports the assumption that there is a major dividing line within the case system between nonoblique cases (nominative and accusative) on the one hand and the remaining cases on the other hand.

The notation "anim $\rightarrow$ gen" refers to a rule familiar in Russian reference grammars, which has it that - under defined conditions - genitive forms are substituted for accusative forms in the presence of the category animate. These alternative accusative forms are known as "genitive-accusatives"; discussion will be deferred to section 2.8.

Maximal gender differentiation only in the non-oblique singular; fewer distinctions in the oblique singular; no gender distinction in the plural, that is, in the marked number - such patterns are familiar from related languages and certainly not random; our analyses of paradigms should take into account 
such systematic asymmetries in paradigms, and this can be done by allowing recourse to superordinate categories.

\subsection{Case Syncretisms}

Turning to case syncretisms, we note that feminine oblique forms of ÈTOT coincide, with the possible exception of the instrumental. The instrumental can be distinguished by a special form of its own (ètoju), but this form counts as literary or obsolete, and whenever it is not used, the plain oblique form (ètoj) takes over. This is an instance of a kind of opposition well known from discussions of markedness. The unmarked form - more precisely, the less marked form (ètoj) - may stand in for the more marked or more "specific" form (ètoju) if the latter is not available or is avoided for some reason.

In the present approach this distribution is accounted for by categorizing ètoj as a plain oblique form - an oblique form without any more specific case categorization - in contrast to the case-specific form ètoju, which is categorized as an instrumental form. As a limiting case of decreasing specificity, a form may be completely unspecific with respect to one or more classifications, say, with respect to case. If so, it will not be assigned a category of the type in question.

Generalizing this approach, we get the underspecified paradigm ÈTOT ${ }^{\text {UP }}$ identified (as a set) in (5). The superscript "UP" stands for "underspecified paradigm"; "genitive-accusative" forms are not included: ${ }^{14}$

(5) ЀтOT $^{\mathrm{UP}}=$

$\{\langle$ ètot, \{\}$\rangle,\langle$ èto, \{non-obl, sg, neut $\}\rangle,\langle$ èta, \{nom, sg, fem $\}\rangle,\langle\grave{e} t u$, $\{$ acc, sg, fem $\}\rangle,\langle\grave{e} t o m,\{$ obl, sg, non-fem $\}\rangle,\langle$ ètim, \{ins, sg, non-fem $\}\rangle$, $\langle$ ètomu, $\{$ dat, sg, non-fem $\}\rangle,\langle e ̀ t o g o,\{$ gen, sg, non-fem $\}\rangle,\langle\grave{e} t o j,\{$ obl, sg, fem $\}\rangle,\langle\grave{e} t o j u,\{$ ins, sg, fem $\}\rangle,\langle\grave{e} t i,\{\mathrm{pl}\}\rangle,\langle\grave{e} t i x,\{\mathrm{obl}, \mathrm{pl}\}\rangle,\langle\grave{e} t i m i$, $\{$ ins, $\mathrm{pl}\}\rangle,\langle\grave{e} t i m,\{$ dat, $\mathrm{pl}\}\rangle\}$

\footnotetext{
${ }^{14}$ The form $\langle\grave{e} t o j u,\{$ ins, sg, fem $\}\rangle$ is included for completeness (cf. Wade $\left.(1992,134 / 154)\right)$ but will, of course, be missing from most registers; similarly for forms in -oju in other paradigms to be discussed below. Nothing of consequence hinges on this decision. On special instrumental singular feminine forms of personal pronouns, see Garde (1980, 254, § 394) and Isačenko $(1962,480)$.
} 
An equivalent graphic representation is given in Table 2, which will be preferred for practical purposes. ${ }^{15}$

\section{Table 2: Underspecified paradigm ÈTOT ${ }^{\mathrm{UP}}$}

\begin{tabular}{|c|c|c|c|c|c|c|}
\hline case & number & gender & form & number & gender & form \\
\hline- & - & - & ètot & $\mathrm{pl}$ & - & èti \\
\hline non-obl & sg & neut & èto & & & \\
\hline nom & $\mathrm{sg}$ & fem & èta & & & \\
\hline acc & $\mathrm{sg}$ & fem & ètu & & & \\
\hline$\overline{\text { obl }}$ & sg & non-fem & ètom & $\mathrm{pl}$ & - & ètix \\
\hline ins & sg & non-fem & ètim & $\mathrm{pl}$ & - & ètimi \\
\hline dat & $\mathrm{sg}$ & non-fem & ètomu & $\mathrm{pl}$ & - & ètim \\
\hline gen & sg & non-fem & ètogo & & & \\
\hline obl & sg & fem & ètoj & & & \\
\hline ins & $\mathrm{sg}$ & fem & ѐtoju & & & \\
\hline
\end{tabular}

What is, traditionally speaking, the nominative singular masculine form is categorized as unmarked for case, number, and gender and hence is assigned the empty categorization $(\{\})$. In paradigmatic tables (such as Table 2 ) the long dash (-) indicates absence of a pertinent category from the categorization; e.g., the categorizations of plural forms listed in Table 2 do not include gender categories, as seen in (5).

Of course, some of the decisions taken in positing this paradigm can find their full justification only within the system of Russian declension taken as a whole. For instance, ètom is categorized as a plain oblique form (of the nonfem sg); it could have been assigned the case category pre (prepositional). This is not done because (i) in other paradigms the ending -om is found in other cases as well; (ii) it turns out that in the complete system of declension the prepositional never exhibits forms that are exclusively its own - the prepositional is always covered by comparatively unspecific forms, hence the category prepositional never occurs in categorizations - and (iii) the corre-

\footnotetext{
${ }^{15}$ In Table 2, read from left to right, for instance, in the row headed by "dat": The dative singular non-feminine form of ЀтОТ is ètomu. The case column applies to singular and plural forms. Hence, from the same row, the dative plural form (which is not specified for gender) of ЀтOT is ètim.
} 
spondence between case categorizations of singular and plural forms would be broken. ${ }^{16}$

If syncretisms are ignored, we get a fully specified paradigm, which in the case of ÈTOT has 36 cells, by cross-classification of all forms for case, number, and gender in terms of terminal categories. ${ }^{17}$ On the other hand, if we allow (i) the absence of categories of a given "dimension" and (ii) nonterminal categories in categorizations, the number of positions is reduced to ten in the singular and five in the plural. Moreover, the look of the system changes: Most forms do have a unique functional characterization (that is, they are related to one and only one categorization). One pair of homonyms is left; the non-feminine instrumental singular form and the dative plural form share their ending (-im).

\subsection{Compatibility and Specificity}

Paradigms must indicate how forms are made up that satisfy a given categorization: Given some categorization as "input", the paradigm should supply the fitting form as "output". We have to make sure that underspecified paradigms as conceived here will still do their job.

That this is so may be seen by considering the following examples; no formal treatment is needed for the purposes of the present essay. First, assume we seek an instrumental singular feminine form of ЀTOT as indicated in (6):

(6) (i) form sought:

(ii) found in paradigm:

\{ins, sg, fem $\}$ of ЀтOT

(iii) condition of fit (equality):

(iv) target identified:

$\langle\grave{e} t o j u,\{$ ins, sg, fem $\}\rangle$

$\{$ ins, sg, fem $\}=\{$ ins, sg, fem $\}$

ètoju

As it happens, the underspecified paradigm EेTOT $^{\mathrm{UP}}$ does contain a form -

\footnotetext{
${ }^{16}$ Note also that the form ètot, which is assigned the empty categorization, is an irregular one, as it exhibits a "formative suffix" -ot (Kortlandt $(1974,64)$ ), or a "Stammerweiterung" ('stem extension'; Mulisch $(1988,260)$ ), which is restricted to the non-oblique singular masculine. While the categorization of ètot may seem debatable, its make-up conforms to the generalization that declensional forms which are assigned the empty categorization do not have endings; it is another matter that forms without endings may require non-empty categorizations (cf. sec. 3.6, infra, on the genitive plural of nouns).

${ }^{17}{ }_{\text {I.e., }}$ Ётот ${ }^{\mathrm{P}}=\{\langle\grave{e}$ tot,$\{$ nom, sg, masc $\}\rangle, \ldots,\langle$ ètom, $\{$ pre, sg, masc $\}\rangle, \ldots,\langle$ ètix, $\{$ gen, pl, fem $\}\rangle\}$. The number of cells of the fully specified paradigm is further increased if "secondary" cases (cf. sec. 3.3, infra) and animacy are taken into account.
} 
given in (6ii) - that has exactly this specification, as confirmed in (6iii). So this is the fitting form, identified as output in (6iv). Of course, searches in a fully specified paradigm would work this way for every form. Hence, equality of categorizations searched for and found would be the proper condition of fit to be satisfied in identifying the correct target form if we were concerned with fully specified paradigms only.

Second, assume we are looking for the dative singular feminine form of ЁTOT, as in (7i). There is no such form in ÈTOT ${ }^{\mathrm{UP}}$, whereas the fitting target form is characterized as a plain oblique form, brought to light in (7ii).

(7) (i) form sought:

$\{$ dat, sg, fem $\}$ of ЀтOT

(ii) found in paradigm:

$\langle\grave{e} t o j,\{\mathrm{obl}, \mathrm{sg}, \mathrm{fem}\}\rangle$

(iii) condition of fit (compatibility): $\cap\{$ dat, sg, fem $\} \subseteq \cap\{$ obl, sg, fem $\}$

(iv) target identified: ètoj

Consequently, we have to relax the condition of fit: Compatibility instead of equality must do. This is to say, a form that has a less specific categorization may stand in when a more specific one is wanting; hence, the categorization found should be equally or less specific than the categorization starting the search.

In an approach that construes categories as sets, specificity can be captured in terms of a subset relation between intersections of categorizations as indicated in (7iii). Assume that is less specific than has been defined (for categorizations, i.e., sets of categories) such that the following holds:

(8) For any non-empty categorizations $C_{1}$ and $C_{2}, C_{2}$ is less specific than $C_{1}$ iff $\cap C_{1} \subset \cap C_{2}$ (i.e., if and only if the intersection of $C_{1}$ is a proper subset of the intersection of $C_{2}$ ).

Then, since dat $\subset$ obl (by (2)), it holds that $\cap\{$ dat, sg, fem $\} \subset \cap\{$ obl, sg, $\mathrm{fem}\}$, which means that the categorization found ( $\{\mathrm{obl}, \mathrm{sg}, \mathrm{fem}\})$ is less specific than the categorization searched for, namely, \{dat, sg, fem $\}$. Further, it is assumed that two categorizations are equally specific if and only if their intersections are equal and that the empty categorization is less specific than any non-empty categorization. ${ }^{18}$

Third, given some categorization to be searched for, there may be more than one compatible form in an underspecified paradigm, as illustrated in (9).

\footnotetext{
${ }^{18}$ This special case may be assimilated to the general intersection-subset-based case of specificity. Given a suitable version of set theory, we may derive that, for any categorization $C, \cap C \subseteq \cap\{\}$ (cf. Suppes $(1972,41)$, theorem (1)).
} 
(9) (i) form sought:

(ii) found in paradigm:

(iii) found in paradigm:

(iv) found in paradigm:

(v) priority (by specificity):

(vi) target identified: \{ins, sg, fem $\}$ of ЀтOT

$\langle$ ètot, \{\}$\rangle$

$\langle\grave{t} t o j,\{$ obl, sg, fem $\}\rangle$

$\langle\grave{t}$ toju, $\{$ ins, sg, fem $\}\rangle$

$\cap\{$ ins, sg, fem $\} \subset \cap\{$ obl, sg, fem $\}$

ètoju

Looking for the instrumental singular feminine form of ЀтOT, we find three compatible forms in ÈTOT ${ }^{\mathrm{UP}}$. First, ètot (9ii) is assigned the empty categorization. In addition, there are two forms with non-empty categorizations, (9iii) and (9iv), which differ in terms of specificity; cf. (9v). In this situation, forms with less specific categorizations have to be ruled out; the most specific one is given priority. This is effected by the principle of specificity, namely: Among a number of compatible categorizations, the most specific one (if any) is the target categorization. ${ }^{19}$ Thus we identify ètoju as the correct target form in Е̇TOT $^{\mathrm{UP}}$, as shown in (9vi). (Of course, in registers that do not allow for the form ètoju the target identified would be ètoj.)

\subsection{Form Categories}

Paradigms as conceived above are relations between word forms and categorizations. As compared to fully specified paradigms, underspecified paradigms help to make transparent how form and function are interrelated in inflection, as illustrated by Е̇тОT ${ }^{\mathrm{UP}}$. However, since we are interested in form-function correspondences not in a single paradigm but in the declensional system as a whole, the next step is to abstract away from the particularities of the example. Hence, we turn to an inspection of relations between form categories (not forms) and categorizations.

A form category (as opposed to a functional category) is a category of forms that share certain formal, namely, expression-related, properties. Rus-

\footnotetext{
${ }^{19}$ Generally, existence of a such a form cannot be taken for granted. Given a categorization to be searched for, there may be two (or more) forms in an underspecified paradigm that exhibit compatible categorizations which are not ordered in terms of specificity. In such circumstances, identification of target forms would have to rely on additional criteria such as relative position in a hierarchy of categories; cf. Kiparsky (1972), Lumsden (1992), among others, and, for a recent discussion, Bobaljik (2002). Additional possibilities for target identification arise when supplementary theorems on relations between categories are taken into account; cf. sec. 2.9, infra, on genitive-accusative equations.
} 
sian declensional word forms such as èta of ÈTOT divide into stem and ending $(e t-a){ }^{20}$ Forms that share certain endings may be collected into form categories. For example, a form category - $a$ may be posited, which is identified as the set of forms that share the same ending with èta, i.e., $-a=\{$ èta, $t a$, nova,...$\}$; names of such categories start with a hyphen.

Using form categories, we may abstract away from differences between related endings in order to bring out what is common to related declensions. In Russian pronominal declension, two subtypes may be distinguished depending on the initial vowel (namely, $i$ or $e$ ) of some of their endings; as a case in point, depending on their endings, dative plural forms of pronouns may fall into either of two form categories, -im or -em. However, choosing to disregard differences between the ending-initial vowels, we may assume a category $-V^{*} m$ defined to cover forms that share endings consisting of one of the vowels $i$ or $e$, followed by $m .{ }^{21}$ Thus, form categories are allowed that are defined by reference to certain types of endings in addition to those defined by reference to particular endings.

All form categories referred to below are defined by reference to endings or types of endings, but of course, there are other formal properties of word forms (e.g., properties relating to stem formation) that would have to be taken into account in a more complete treatment of Russian declension (and thus in a more complete system of form categories). As these are beyond the scope of the present analysis, we may speak informally of, say, "the ending $-a$ " or, even more loosely, "the ending $-V^{*} m$ " when we refer to some form category (such as $-a$ or $-V^{*} m$ ).

Generalizing the paradigm represented in Table 2, we arrive at the paradigm scheme represented in Table 3, which represents a relation between form categories (endings or ending types) and categorizations. ${ }^{22}$ For convenience, reference numbers - prefixed "S" or "P" for "singular" or "plural" -

\footnotetext{
${ }^{20}$ Endings and their morphophonemic analyses are assumed as in Jakobson (1958); for a possible minor deviation, cf. note 50, infra. For listings and discussion of noun endings in particular, see Stankiewicz (1968) and Corbett (1982).

${ }^{21}$ Hence, both $-i m$ and $-e m$ are subsets of $-V^{*} m$. Very informally, a category like $-V^{*} m$ is "more abstract" than -em since determination of the latter involves a comparatively "more specific" set of properties. However, use of superordinate form categories does not involve in any way the introduction of "abstract" or "deep" entities (say, an "abstract vowel" $V^{*}$ ).

${ }^{22}$ In a paradigm, forms (say, ètomu) are related to categorizations (sets of functional categories); in paradigm schemes, it is form categories (e.g., - Vmu) that are related to categorizations. Cf. Lieb (2003) for a developed approach to relations between form categories and functional categories (see op. cit., sec. 4.6, in particular, on the notion of system link).
} 
have been added that refer to the categorizations indicated; "0" refers to the empty categorization. This is only for ease of discussion; reference numbers are not part of paradigms or paradigm schemes, of course. As paradigms and paradigm schemes are sets, their elements are unordered; no extrinsic ordering is assumed. Expressions such as "the S6-ending" will be used to refer to the ending related to the categorization so numbered. ${ }^{23}$

Table 3: Pronominal declension: general endings

\begin{tabular}{|c|c|c|c|c|c|c|c|c|}
\hline case & number & gender & ending & $\#$ & number & gender & ending & \# \\
\hline- & - & - & - & 0 & $\mathrm{pl}$ & - & $-V^{*}$ & $\mathrm{P} 1$ \\
\hline non-obl & sg & neut & $-V$ & $\mathrm{~S} 1$ & & & & \\
\hline nom & $\mathrm{sg}$ & fem & $-a$ & S2 & & & & \\
\hline acc & sg & fem & $-u$ & S3 & & & & \\
\hline obl & $\mathrm{sg}$ & non-fem & $-V m$ & S4 & $\mathrm{pl}$ & - & $-V^{*} x$ & $\overline{\mathrm{P} 3}$ \\
\hline ins & $\mathrm{sg}$ & non-fem & $-V^{*} m$ & S5 & $\mathrm{pl}$ & - & $-V^{*} m^{\prime} i$ & P4 \\
\hline dat & sg & non-fem & -Vmu & S6 & $\mathrm{pl}$ & - & $-V^{*} m$ & P5 \\
\hline gen & $\mathrm{sg}$ & non-fem & $-V v o$ & S7 & & & & \\
\hline$\overline{\text { obl }}$ & $\overline{s g}$ & fem & $-V j$ & $\overline{S 8}$ & & & & \\
\hline ins & sg & fem & $-V j u$ & S9 & & & & \\
\hline
\end{tabular}

Ending-initial vowels: $o$ in $V$-endings, $i$ or $e$ in $V^{*}$-endings

The two subtypes of pronominal declension mentioned differ in the initial vowels (namely, $i$ or $e$ ) of plural endings and of the non-feminine instrumental singular ending. In Table 3, I have abstracted away from this subtype differentiation by positing the form categories $-V^{*},-V^{*} m,-V^{*} x$, and $-V^{*} m^{\prime} i$, subsuming forms that show $i$ or $e$ as their ending-initial vowels. The remaining oblique forms of the singular have $o$ as their initial vowel, which is also found in the S1-ending. This vowel may be regarded as the "default vowel" in Russian declensional endings; names of pertinent categories (e.g., $-\mathrm{Vm}$ ) are formed using the symbol "V" unmodified. (For the endings in question I shall use the term $V$-endings; and similarly, $V^{*}$-endings). ${ }^{24}$

\footnotetext{
23"P2" is left for use with noun endings (cf. sec. 3.6).

${ }^{24} \mathrm{Cf}$. Halle (1994) on theme vowels in Russian; $o$ also serves as a linking vowel in compounds (Unbegaun $(1957,90)$ ). According to Garde $(1980,251, \S 388)$ it is the type of stemfinal consonant (obstruent vs. sonorant) which conditions the choice of the initial vowel of the $V^{*}$-endings. As a minor complication, neglected in the text for simplicity of presentation, note
} 
All of the endings (or ending types) listed and related to categorizations in Table 3 appear with more than one of the three word classes of declinables - pronoun, adjective, and noun - and will be referred to, therefore, as general endings (in contradistinction to endings that are specific to only one of these word classes). ${ }^{25}$

\subsection{Correspondences of Form and Function}

Morphological marking of inflectional categories has often been noticed to be patently iconic, and underspecification helps to throw into relief the constructional "diagrammaticity" of the make-up of inflectional word forms in Russian declension in particular. As may be read off Table 3, complexity of formal marking (here, complexity of endings) corresponds to complexity of function (here, complexity of categorization); as a limiting case, absence of formal marking (absence of ending) corresponds to lack of functional specification, hence relates to the empty categorization. Even more generally, similarity of form (similarity of endings) corresponds to similarity of function (similarity of categorization). ${ }^{26}$

A detailed analysis of form-function iconicity is not among the goals of the present discussion. May it suffice to note that iconicity is observable when oblique cases exhibit long ending, i.e., endings involving at least one vowel and one consonant, while the remaining forms exhibit short endings, i.e., endings made up of a single vowel, or no ending at all. Among oblique forms, it is the singular plain oblique forms where least-marked (two-phoneme) endings are found $(-V m$, non-fem, and $-V j$, fem). More specific oblique singular non-feminine forms exhibit three types of complex markers that involve vowel change (in the instrumental, $V$ to $V^{*}$, also employed for plural marking) or formation of extra long (three-phoneme) forms where the additional final vowel is the default ending vowel (in the genitive, -ovo) or is the ending vowel $u$ (in the dative, -omu). All of these non-fem endings are related by including labial consonants.

that the ending-initial vowel in $V$-endings may be $e$ (instead of $o$ ) in the oblique cases of the fem forms of pronouns (namely, if the vowel is preceded by a soft consonant, op. cit. p. 251, $\S 388$; cf. also Unbegaun $(1957,132 / 134))$.

${ }^{25}$ For endings specific to adjectives and to nouns, see sec. 2.7 and sec. 3, infra, respectively. For a pronoun-only ending see note 27 , infra.

${ }^{26}$ On iconicity in Russian inflection, see Jakobson (1958) and references given in note 56, infra; in a more general vein, Jakobson (1965). Cf. also Matthews (1991, 234). 
On the other hand, the feminine employs only the third technique mentioned, addition of $u$ ( $-o j$ vs. $-o j u$ ), exhibiting as it does a drastically reduced differentiation of oblique cases - plain vs. (optionally) instrumental - being the marked member of the superordinate gender classification. ${ }^{27}$ Conspicuously, feminine endings do not include labial consonants.

\subsection{Adjectival Endings}

The standard declension of adjectives differs from that of pronouns by showing long forms - forms that exhibit long endings - in non-oblique cases. As compared to pronominal forms, in these adjectival forms the stem is followed by an extra vowel+yod, followed in its turn by what would be the expected vowel, if any, in the case of a pronoun ending. Where endings from the general inventory (as given in Table 3) are long anyway (viz., in oblique cases), such extension does not apply; hence, in the oblique cases, formation of adjective forms conforms to the general pattern. The vowel of the extension element is the same as the vowel of the corresponding general ending, if any; otherwise, the default ending vowel $o$ is used. ${ }^{28}$ Special long endings of adjectives are listed in Table $4 .{ }^{29}$ Case-number-gender categorizations are the same as for short counterparts (as indicated by the reference numbers).

Depending on subclass, adjectives possess both short and long variants of

\footnotetext{
${ }^{27}$ Actually, a feminine counterpart of the non-feminine genitive singular endings -ovo does exist, viz., -ojo (Kortlandt $(1974,66))$ or -ejo (Garde $(1980,254))$, to be categorized as $\{$ gen, sg, fem \} (which, not being a general ending, is not included in Table 3). This ending does not occur in regular paradigms but is found with the genitive(-accusative) form of the third person personal pronoun $\mathrm{ON}$ where it competes with the general ending. The remaining endings of the forms of ON are from the standard inventory; for details, see Garde op. cit., pp. 253f., $\S$ 394 , on $e$ in $V$-endings, cf. note 24 , supra, and see also op. cit. pp. $273 f$., $\$ \S 431,433$, on -ojo used with fem-forms of $\mathrm{VES}^{\prime}$ and SAM. For forms of non-gendered personal pronouns, see sec. 3.8 , infra.

${ }^{28}$ If unaccented, the long 0-ending appears as -ij instead of -oj; see Unbegaun $(1957,97)$, on "recent" vs. "traditional pronunciation", and cf. Garde (1980, 208, § 309), Cubberley (2002, $131)$.

${ }^{29}$ Endings are given in morphophonemic transcription, again following Jakobson (1958); cf. also Halle \& Matushansky (2003, Table 1). The degree of correspondence between short and long forms that can be claimed varies between different (morphophonological, and indeed phonetic) analyses. The long P1-ending is more usually rendered as -ije (e.g., in Garde (1980, 208 ), $\S 308$ ). Note, however, that the pronunciation of the final vowel of this ending is "normally [l]" (Timberlake $(2004,51)$ ); cf. op. cit. pp. 48-51 for a discussion of the pronunciation of vowels in inflectional endings.
} 
Table 4: Adjectival declension: general and long endings (non-oblique cases)

\begin{tabular}{|c|c|c|}
\hline $\begin{array}{c}\text { short general endings } \\
-v\end{array}$ & $\begin{array}{c}\text { long adjectival endings } \\
-v j(v)\end{array}$ & $\#$ \\
\hline- & $-o j$ & 0 \\
\hline$-o$ & $-o j o$ & $\mathrm{~S} 1$ \\
\hline \hline$-a$ & $-a j a$ & $\mathrm{~S} 2$ \\
\hline$-u$ & $-u j u$ & $\mathrm{~S} 3$ \\
\hline \hline$-i$ & $-i j i$ & $\mathrm{P} 1$ \\
\hline
\end{tabular}

Construction of long adjectival endings:

$-v j v$, where $v$ is as in standard endings (if present, otherwise -ój $\sim i j$ ).

non-oblique singular endings, only long variants, or only short variants. ${ }^{30}$ The make-up of special adjectival endings is transparent. They are but lengthened versions of their general counterparts (as found with pronouns). In oblique cases, general endings apply throughout. Thus, the differentiation of general endings and special adjectival endings is made only in non-oblique cases, hence in what is the less-marked domain in terms of case marking. Not unexpectedly, the more marked domain lacks a subdivision that is present in the less marked domain. The non-oblique/oblique distinction shows up again as reflecting a basic division in Russian paradigms.

\subsection{Differential Object Marking}

Singular vs. plural and non-oblique vs. oblique have been identified as major divisions splitting up Russian paradigms into four quarters or subparadigms; accordingly, in Table 3 case endings have been collected into four boxes. The subparadigms so specified provide the domains of syncretism of case treated above in terms of underspecification.

Syncretism of the two core cases, namely - characterized in terms of their primary functions - nominative as the subject case and accusative as

\footnotetext{
${ }^{30}$ See Wade $(1992,153-192)$ and other reference grammars for conditions of use and classification of adjectives, in particular Unbegaun (1957, 100-102) on possessive and relative adjectives that do not employ the lengthened forms but follow the general pattern. The standard adjective declension also includes various groups of words that are usually classified as pronouns; for a short survey, see Cubberley $(2002,131 \mathrm{f}$.). Adjectival declension is also found with participles.
} 
the (direct) object case, is a cross-linguistically widespread phenomenon and is widespread in Russian declension. However, it is an equally widespread phenomenon that, in spite of general syncretism, some, but not all, objects do require morphological marking depending on factors that include, most prominently, definiteness and animacy. Given definiteness and animacy as scalar dimensions, nominals that are high on the definiteness scale and/or high on the animacy scale are "unexpected" as objects, being typical subjects, and tend to call for overt marking when figuring as objects, while otherwise objects may be left without explicit distinction. This is referred to as differential object marking (DOM). ${ }^{31}$ Often, and perhaps typically, DOM appears as syncretism between marked object forms (accusative forms) and forms of some oblique case: In declensional systems (or subsystems thereof) that lack special accusative forms, functional demands may force, as it were, oblique case forms into the service of (direct) object marking.

As for case marking in Russian, the animacy scale reduces to a dichotomy between animate and inanimate; similarly, the definiteness scale provides the basis for opposing personal pronouns, which are at the top of this scale, to the remainder of nominals. This means that the domain of application for DOM in Russian is restricted to the categories animate and personal pronoun. Morphologically, the oblique case forms that serve for DOM in Russian are forms that appear in the genitive otherwise - whence the name genitive-accusative. These are either special genitive forms (e.g., the non-feminine genitive singular form ètogo of ЕेтОT) or plain oblique forms where such forms cover the genitive (e.g., the plain oblique plural form ètix of ЀTOT). Personal pronouns show genitive-accusatives throughout, irrespective of animacy; thus, genitive forms of the personal pronoun of the third person on (ego, non-feminine singular; $e \ddot{e}$, feminine singular; $i x$, plural) are also used as accusatives in referring to inanimates.

Outside the category of personal pronouns, there is another factor that partly controls DOM in Russian in addition to animacy and definiteness namely, gender. As may be gathered from Table 1, in pronominal declension, DOM does not apply in the marked genders feminine and neuter. Of

\footnotetext{
${ }^{31}$ Bossong (1998, with references); cf. also Thomson (1909/1912), Lyons (1968, sec. 7.4.3f.), Comrie (1978; 1981, sec. 6.2.2), and Aissen (2003, with further references). Following Aissen, op. cit., p. 437, the animacy scale and the definiteness scale may be set up as in (i) and (ii), respectively: (i) Human $>$ Animate $>$ Inanimate, (ii) Personal pronoun $>$ Proper name $>$ Definite NP $>$ Indefinite specific NP $>$ Non-specific NP. Comrie $(1978,39)$ uses the term "scale of referent identifiability".
} 
course, this restriction is operative in the singular only, since there is no differentiation of gender forms in the plural in Russian; agreeing items such as pronouns and adjectives never exhibit gender distinctions in the plural. ${ }^{32}$ From a functional point of view, not much is lost due to the lack of DOM in the feminine and neuter singular, for opposite reasons. In the feminine, there is non-differential object marking; i.e., pronouns like ЀTOT (and adjectives as well) possess special accusative feminine forms that apply regardless of animacy (cf. S3 in Table 3). Because in such (sub)paradigms the accusative singular feminine has a form of its own even for inanimates, no DOM is called for: Non-differential object marking "blocks" differential object marking. Neuters on the other hand are - with rare exceptions - inanimate and would not call for DOM either. Thus, it is only natural that DOM does not apply either in the feminine singular or in the neuter singular. ${ }^{33}$

At the same time, gender-related restriction of DOM may be regarded as a manifestation of Brøndal's "principe de compensation", which disfavors clustering of categorial markers, a standard example being the (partial or total) suppression of gender differentiation in the plural: Where number and gender marking collide, marked number may oust gender marking. Similarly, in the singular, which does exhibit gender differentiation, marked genders (feminine and neuter) do not countenance differentiation into animate and inanimate forms; gender thus proves to be dominant over subgender. ${ }^{34}$

\subsection{Genitive-Accusative Equations}

It remains to make sure that searching for animate accusative forms in underspecified paradigms such as ĖTOT ${ }^{\mathrm{UP}}$, as given in (5) or, equivalently, in Table 2 , returns the correct targets. ${ }^{35}$

On the basis of the preceding discussion the equations in (10) and (11) may be established.

\footnotetext{
${ }^{32}$ For the exceptional paradigms of OBA ('both') and DVA ('two'), see Garde (1980, 235, § $364)$. It is another matter that there are gender-specific differences in the formation of plural noun forms, cf. sec. 3.6.

${ }^{33} \mathrm{Cf}$. Comrie (1978). On declension class as a factor that restricts applicability of DOM (with nouns), see sec. 2.9.

${ }^{34}$ Cf. Brøndal (1940). The term "dominant" is Hjelmslev's (see Hjelmslev (1956) for extensive discussion of animacy and case syncretism in Russian and other Slavonic languages).

${ }^{35} \mathrm{Cf}$. Blevins (this volume). I take it that genitive-accusative syncretism should not be treated as a case of neutralization to be handled by underspecification; cf. sec. 4 for arguments to this effect.
} 
(10) For personal pronouns:

acc $=$ gen

(11) For other declinable non-nouns:

(i) $\cap\{$ acc, sg, masc, anim $\}=\cap\{$ gen, sg, masc, anim $\}$

(ii) $\cap\{$ acc, pl, anim $\}=\cap\{$ gen, pl, anim $\}$

The equation in (10) says that the set of accusative forms of personal pronouns equals the set of genitive forms of personal pronouns. The equations in (11) say that, for other pronouns and adjectives, (i) the set of accusative singular masculine animate forms equals the set of genitive singular animate masculine forms, and (ii) the set of accusative plural animate forms equals the set of genitive plural animate forms. Presumably, these equations represent true statements about Russian declension that have to be integrated in one way or another into any reasonable treatment of the subject. Hence, we assume that (10) and (11) are given and may be made use of in the identification of declensional forms. On this assumption, no further extra mechanisms or special theoretical constructs are needed to deal with accusative-genitive forms of adjectives and pronouns, as may be gathered from inspection of the example search in (12).

(12) (i) form sought:

(ii) found in paradigm:

$\{$ acc, sg, masc, anim $\}$ of ЀтоT

(iii) $[=(11 \mathrm{i})]$

$\langle$ ètot, \{\}$\rangle$

(iv) found in paradigm:

(v) by (3i):

$\cap\{$ acc, sg, masc, anim $\}=\cap\{$ gen, sg, masc, anim $\}$

(vi) by (v):

$\langle$ ètogo, $\{$ gen, sg, non-fem $\}\rangle$

masc $\subseteq$ non-fem

(vii) condition of fit:

(compatibility)

(viii) target identified:

$\cap\{$ gen, sg, masc, anim $\} \subseteq \cap\{$ gen, sg, non-fem $\}$

$\cap\{$ acc, sg, masc, anim $\} \subseteq\{$ gen, sg, non-fem $\}$

ètogo

Assume we are looking for the accusative singular masculine animate form of ЁТОT (12i), or rather the most specific compatible form in ЀтоT ${ }^{\mathrm{UP}}$. The form ètot satisfies the compatibility requirement, its categorization being empty, as shown in (12ii), taken from (5); prima facie ètot seems to be the only form that exhibits a compatible categorization. However, crucially, we may avail ourselves of assumption (11i), repeated as (12iii). Now, consider ètogo with its categorization in (12iv), again taken from (5). Given the classification system for gender assumed in (3i), we have (12v), whence (12vi). Step (12vii) follows from (12iii) and (12vi). It turns out that the form ètogo is a compatible target given the categorization in the "form sought" line: As 
shown in (12), using (11) it can be proven that $\cap \mathrm{C}_{1} \subseteq \cap \mathrm{C}_{2}$ (cf. 12vii), where $\mathrm{C}_{1}=_{\text {def }}\{$ acc, sg, masc, anim $\}$ as in (12i) and $\mathrm{C}_{2}={ }_{\text {def }}\{\mathrm{gen}, \mathrm{sg}$, non-fem $\}$ as in (12iv); hence, a compatibility relation exists. Since the only other compatible categorization in EेTOT ${ }^{\mathrm{UP}}$ is the empty categorization, the correct target form is identified as in (12viii), using the principle of specificity, following (8). Similarly, we identify ètix as the accusative plural animate form (for all genders). ${ }^{36}$

Mutatis mutandis, the equations in (11) apply to nouns, too. Because nouns have inherent, thus invariable, gender, reference to the category of masculine forms as in (11i) must be removed; it is replaced by reference to the masculine declension type. ${ }^{37}$ Similarly, for animacy. The following equation will be assumed to be given: $\cap\{$ acc, sg $\}=\cap\{$ gen, sg $\}$, for forms of animate nouns of the masculine declension type. Equation (11ii), which includes no reference to gender, applies to nouns with analogous modification: It is assumed that $\cap\{$ acc, $\mathrm{pl}\}=\cap\{$ gen, $\mathrm{pl}\}$, for forms of animate nouns. ${ }^{38}$

\section{Nouns}

\subsection{General vs. Noun-Specific Endings}

Most endings discussed in section 2 apply not only to pronouns and adjectives but (partly modified) also to nouns. Hence, the inventory listed in Table 3 appropriately serves as a point of departure for the analysis of the declension

\footnotetext{
${ }^{36} \mathrm{By}(2)$, gen $\subseteq$ obl, whence $\cap\{$ gen, $\mathrm{pl}\} \subseteq \cap\{$ obl, pl $\}$; from the preceding and (11ii), viz., $\cap\{$ acc, pl, anim $\}=\cap\{$ gen, pl, anim $\}$, it follows that $\cap\{$ acc, pl, anim $\} \subseteq \cap\{$ obl, pl $\}$. Hence the form ètix, which is categorized as $\{\mathrm{obl}, \mathrm{pl}\}$ in ЀTOT $^{\mathrm{UP}}$, has a categorization that is compatible with the categorization starting the search, viz., $\{$ acc, pl, anim $\}$ for any gender; this is also true of the forms èti (P1) and ètot (0), the categorizations of which are, however, less specific.

${ }^{37}$ I.e., declension IA; cf. sec. 3.2, infra, for noun declensions. This treatment implies (as it should) that those animate feminine nouns (like MAT' ('mother')) that have nominativeaccusative syncretism as well as neuter animate nouns like ČUDOVIŠČE ('monster') still do not show DOM in the singular (although neuters may exhibit some fluctuation, Corbett (1991, $43)$ ). Both types of animates are rare, anyway, obviously so for neuters; cf. Garde (1980, § 264), on animate nouns of declension III. Nouns of declension II show non-differential object marking in the singular, hence no DOM, irrespective of gender. Note that the genitive II (cf. sec. 3.3., infra) is restricted to inanimates (Stankiewicz $(1968,31)$ ).

${ }^{38}$ The fact that Russian animate nouns of all genders show genitive-accusatives in the plural may be taken to "reflect the tendency for gender and declensional class distinctions to be lost completely in the plural" (Comrie 1978, 39).
} 
of nouns to be given in the present section. There are also a few additions to be made, that is, endings with categorizations that are found with nouns only will have to be incorporated. This leads to a refined version of the case system given in (2), above. Perhaps somewhat surprisingly, the overall picture of form-function correlations is not changed very much by extending the analysis to nouns.

I shall take as a basis the fourfold division of the inventory according to the two major divisions singular/plural and non-oblique/oblique; peculiarities of noun inflection that pertain to the four subdomains will be taken up in their turn. In addition, section 3.2 serves to present the structure of the system of declension types, while section 3.4 develops in full the structure of the case system. Genitive-accusatives of nouns have already been dealt with in section 2.9 and require no further treatment. ${ }^{39}$

\subsection{Non-Oblique Singular Noun Endings and Declension Types}

The analysis of Russian pronominal and adjectival inflection in the preceding section did not necessitate a division into declension classes. Russian declension is simpler than the declension of some related languages, such as Classical Latin. Consider Latin adjectives like bonus/bona/bonum ('good'). Such adjectives combine the gender-related patterns of the Latin first and second declensions of nouns, which, as a rule, comprise feminine and nonfeminine nouns, respectively. With adjectives, the endings of gender-related declensions are used to derive gender-specific forms, viz., feminine and nonfeminine (masculine and neuter) forms. However, differently from Russian, other adjectives like brevis ('short') follow another declension, the third declension, and these adjectives differentiate genders using gender-related sets of endings, too. Thus, for adjectives in Latin, the first and second declensions combine into what may be called a "macrodeclension"; put differently (and perhaps more appropriately), declensions come in groups. Although noun declensions are often listed individually in traditional grammars, the grouping of declensional patterns that is operative in adjective declension is also relevant for noun inflection. ${ }^{40}$

A similar correspondence between gender-related noun declensions and

\footnotetext{
${ }^{39}$ For further general discussion of genitive-accusatives, see sec. 4, infra.

${ }^{40}$ For the pros and cons of "macrodeclensions" and "macroparadigms", see Blevins (this volume).
} 
adjectival genders is found in Russian, as may be seen from an inspection of non-oblique singular endings displayed in Table 5.

Table 5: Noun declensions: endings in non-oblique singular cases

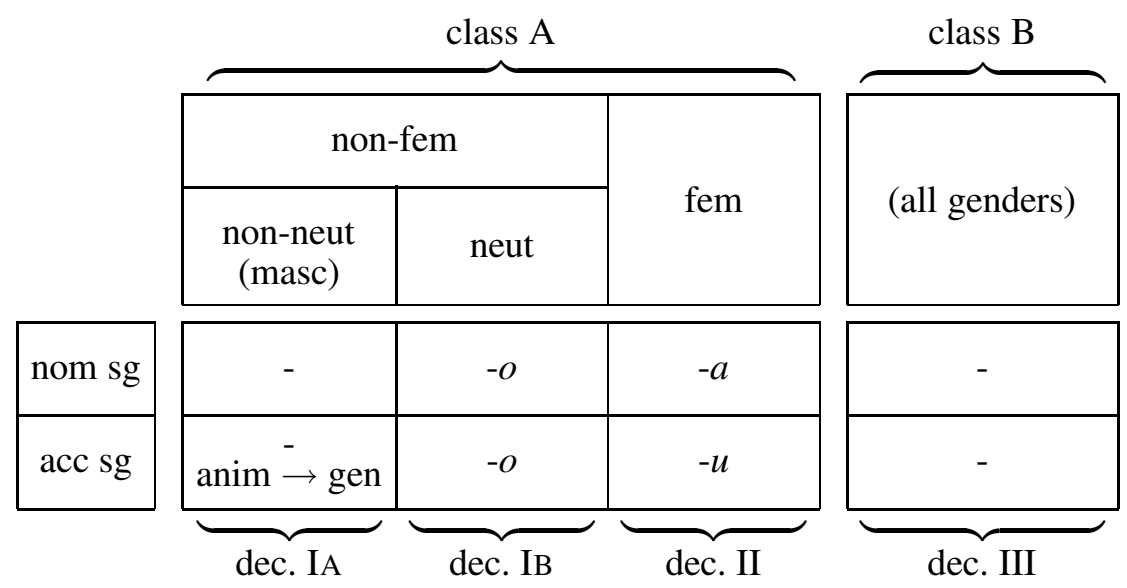

\section{Examples:}

STUDENT ('student'), masc, anim, IA; ZAKON ('law'), masc, inanim, IA; VINO ('wine'), neut, IB; GORA ('mountain'), fem, II; PUT' ('way'), masc, III; VREMJA ('time'), neut, III; KOST' ('bone'), fem, III

Most Russian reference grammars distinguish three noun declensions. There is a straightforward correlation between gender and declension, dec. I being restricted to non-feminines, while dec. II nouns are, as a rule, feminines. As usual, the non-feminine declension splits into a masculine (nonneuter) and a neuter subtype (declensions IA and Iв) that differ in non-oblique cases; for example nouns, see Table $5 .{ }^{41}$

As in comparable systems, the correlation between gender and declension is not one-to-one but deviations are severely constrained in Russian. In particular, there is a limited group of nouns in dec. II that denote male persons.

\footnotetext{
${ }^{41}$ Cf. Timberlake (2004). Numbering (I vs. II) is as in various recent treatments (but the reverse of traditional declension numbers and the designations for Latin declensions); see also Cubberley $(2002,111)$, with references. Corbett (1982, with references) provides a comprehensive discussion of alternative proposals for grouping declensions; see esp. sec. 3.3 on the "two-paradigm solution (Zaliznjak version)". For a seeming split of the non-fem type in an oblique case, namely, in the genitive plural, see sec. 3.6, infra.
} 
These are masculine due to an overriding semantically based rule, namely: Sex-differentiable nouns denoting male and female persons or higher animals are masculine and feminine, respectively. ${ }^{42}$ This said, masculine nouns of the second declension may be safely ignored in an analysis of declensional paradigms and endings; they are declined exactly as are feminine ones. These nouns may be added on without any complications if the morphological analysis is completed. In what follows, I exclude from consideration nouns where declension type and gender do not fit, replacing somewhat cumbersome references to, say, "nouns of the feminine declension type" by more simple references to "feminine nouns". 43

The endings of the non-oblique singular cases of declensions IA, IB, and II are taken from the general inventory, with categorizations undergoing obvious modifications: As nouns have inherent (invariable) gender, reference to genders of forms has to be replaced by reference to corresponding genders of lexemes ${ }^{44}$ Apart from this, endings $-o,-a$, and $-u$ reappear with their standard values; also, use of forms without endings and use of genitive-accusatives in the masculine does not deviate from the general pattern. In essence, the formfunction correlation is the same as found with non-nouns. "Marker sharing" between nouns and non-nouns, familiar from older Indo-European languages, continues on in Russian.

Declensions IA, IB, and II form a natural group, since they participate in the ubiquitous pattern of gender differentiation in the nominative singular that is also found with pronouns, adjectives, and participles (and with past forms of verbs), where feminine forms terminate in $a$, neuter forms terminate in $o$, and masculine forms terminate in non-vowels. Declensions IA, IB and II are the most important, the most productive, and in fact, the unmarked types of noun inflection. ${ }^{45}$ As a group, these declensions stand in opposition to dec. III, a declension that has, in Russian, no counterpart among non-nouns. In this declension, non-oblique singular forms always come without endings, regardless of gender and subgender. The overwhelming majority of dec. III nouns are feminines; there are a handful of neuters, and there is only one

\footnotetext{
${ }^{42}$ Corbett (1991, 34, for discussion: 34-43), based on Corbett (1982); cf. Comrie (1978).

${ }^{43}$ This also excludes discussion of special features of the declension of augmentatives and other expressive derivatives, for which see Stankiewicz $(1968,107-8)$. On nouns of "common gender" see op. cit., p. 18. Cf. also Corbett (1982, 220-3; 1991, 183f. and passim).

${ }^{44}$ Alternatively, it may be assumed that inflectional forms of, say, masculine lexemes are masculine forms in their turn; i.e., forms may "inherit" the gender of their lexemes.

${ }^{45}$ Cf. Corbett $(1982,208)$.
} 
masculine noun in dec. III (viz., PUT' ('way')). ${ }^{46}$ Since in oblique cases inflection differs according to gender, the so-called third declension of Russian may actually be regarded as forming a group of (three) gender-related declensions, however deficient this group appears with regard to the number of non-feminine items as well as its overall elaboration. ${ }^{47}$

It seems natural, then, to posit a major division between nouns of declension I and II on the one hand, henceforth class A nouns, and nouns of declension III on the other hand, henceforth class B nouns. These labels are suggested because it seems that, unfortunately, there are no received, wellestablished terms for such groups of related declensions, at least as applied to Russian. ${ }^{48}$ In sum, declensions do not exist in isolation but fit into a crossclassification which is based on the major class division (class A vs. class B nouns) and on the division of genders (or, to be precise, gender-related declension types). ${ }^{49}$

Endings occurring in non-oblique singular forms of nouns are categorized in Table 6. As compared to Table 3, no new endings or categorizations are needed. Note, however, that class B nouns do not show formal distinctions in the direct singular cases; i.e., these nouns do not accept S1-, S2-, and S3endings; as a result, forms without endings appear instead. To take note of this fact, columns have been introduced into Table 6 where plus and minus signs indicate whether form-categorization pairs are applicable with class A nouns, class B nouns, and/or other regularly declined items. ${ }^{50}$

\footnotetext{
${ }^{46}$ Feminines are mostly derived abstracts in -ost' like starost' ('old age'), but a number of familiar simplex nouns are included (Unbegaun $(1957,64)$ ). Neuters of the VREMJA-type are sometimes included in dec. III, sometimes treated as irregulars; cf. Isačenko (1962), Garde (1980, on "Les hétéroclites", §§ 279-281).

${ }^{47}$ Timberlake (2004, 143); cf. also Stankiewicz $(1968,25)$

${ }^{48}$ For Old Church Slavonic, the terms "twofold nominal declension" (dec. I+II, $o$ - and $a$ stems) and "simple nominal declension" (dec. III, $i$-stems) have been used; see Lunt (2001). Cf. also Jakobson (1958) on "secondary" paradigms (dec. III) in contrast to the standard ones.

${ }^{49}$ A comparable cross-classificatory approach to Latin declensions has been proposed in Wiese (2002). For a (substantially rather different) cross-classificatory approach to Russian declensions embedded in a feature-based framework, see Müller (this volume).

${ }^{50}$ According to the analysis of Jakobson (1958, sec. 3.6), adopted in Stankiewicz (1968), also assumed in Garde (1980), the non-oblique singular forms of neuter class B nouns (as vremja of VREMJA) do not lack an ending (as assumed here, following, among others, Corbett (1982)), but show, in a morphophonological analysis, the ending -o. If this assumption is adopted, all that has to be done is to change minus to plus in the B-column of the S1-row.
} 
Table 6: Categorizations of noun endings: non-oblique singular cases

\begin{tabular}{|c|c|c|c|c|c|c|c|}
\hline case & number & gender & ending & $\#$ & $\mathrm{O}$ & $\mathrm{A}$ & $\mathrm{B}$ \\
\hline \hline- & - & - & - & 0 & + & + & + \\
\hline non-obl & $\mathrm{sg}$ & neut & $-o$ & $\mathrm{~S} 1$ & + & + & - \\
\hline nom & $\mathrm{sg}$ & fem & $-a$ & $\mathrm{~S} 2$ & + & + & - \\
\hline acc & $\mathrm{sg}$ & fem & $-u$ & $\mathrm{~S} 3$ & + & + & - \\
\hline
\end{tabular}

Class A nouns (A), class B nouns (B), other standard declinables (O), ,-+ : (non-)applicable

\subsection{Oblique Singular Noun Endings}

Oblique singular endings and their distribution over noun declensions are shown in Table 7. It is in the oblique singular cases that noun declension shows its most striking peculiarities. First, a subclass of masculine class A nouns distinguish two types of prepositional case forms and/or two types of genitive case forms. Thus two extra cases ("secondary" or "accessory" cases) have to be assumed, known as prepositional II and genitive II; using more informative names, these cases may also be referred to as locative and partitive, respectively (abbreviated pre II or loc, and gen II or par). Some specialists in Russian grammar hesitate to accept these cases, since these rather restricted phenomena would appear to lead to significant complications in the overall system. No such problem arises in an approach that takes advantage of underspecification; in particular, integration of loc and par does not demand any changes in the analysis of non-noun declension given in section $2 .{ }^{51}$ An example noun showing both special locative and partitive forms is SNEG ('snow'); the oblique singular endings are as given in Table 7 in the column headed "non-neut"; the majority of class A masculines (and class A neuters in general) show the set of endings given in the adjacent column headed "non-fem" (for example nouns, see Table 5).

Second, a detailed examination of the formal divisions found in the oblique singular domain, as laid out in Table 7, leads to the conclusion that

\footnotetext{
${ }^{51}$ Another terminology has "locative I/II" for "prepositional I/II"; cf., e.g., Garde (1980). The prepositional II is, as Stankiewicz $(1968,35)$ puts it, "conspicuously a localistic case", hence may be referred to as locative. For a concise discussion of the conditions of use for par and loc, see Comrie, Stone \& Polinsky (1996, 124-127). For restrictions of applicability of the partitive, see Stankiewicz (1968, 31ff.). Underspecification as an approach to secondary cases is proposed in Comrie (1986).
} 
Table 7: Noun declensions: endings in oblique singular cases

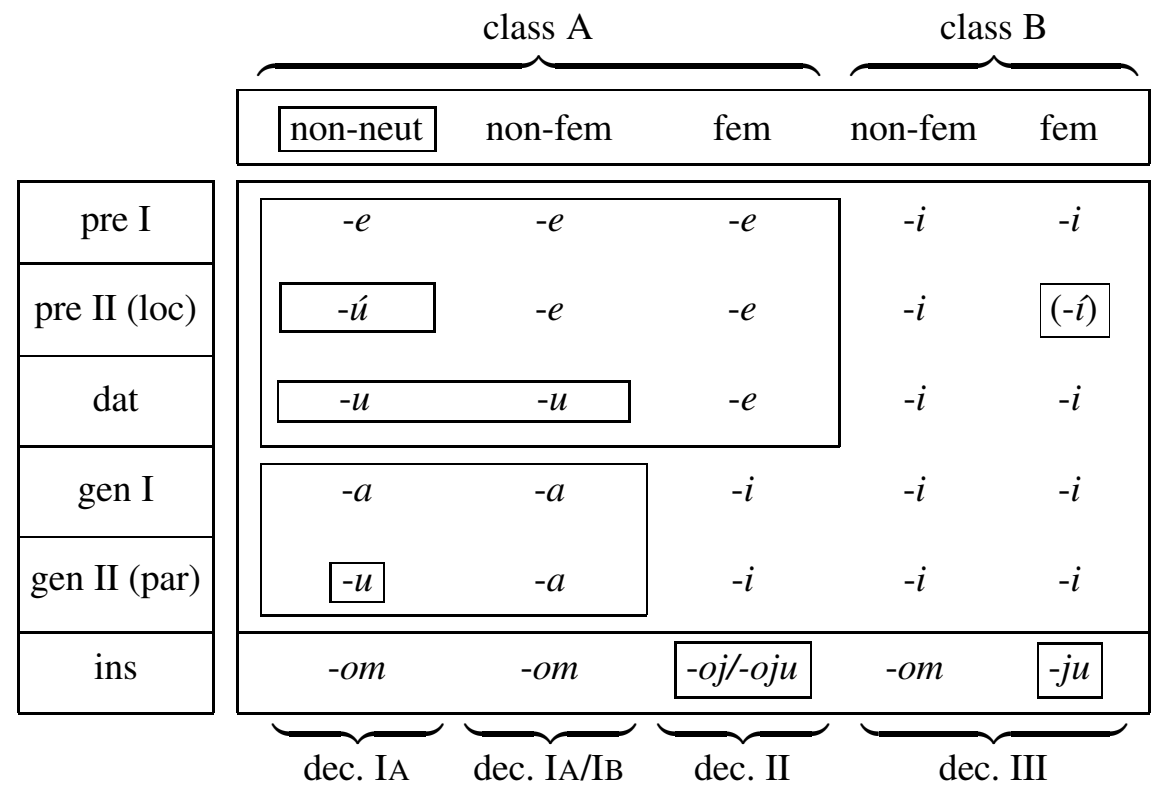

the system of case classifications involves, so to speak, "more hierarchy" than had been apparent before. Within the domain of oblique cases a major division stands out: Only instrumental forms use general endings, whereas the remaining oblique singular case forms of nouns show endings that are (in this function) specific to nouns. They differ formally, too: The former are long, the latter are short. ${ }^{52}$ Moreover, the major factor controlling choice of instrumental endings is gender (non-fem vs. fem), while the distribution of the remaining endings is more complex, class A vs. class B membership intervening more strongly.

Instrumental case endings are taken from the general inventory without changes in categorizations (cf. Table 3). Instrumental forms of class A feminines show the alternation between -oj and -oju known from the corresponding forms of pronouns and adjectives, i.e., between S8- and S9-endings (categorized as $\{\mathrm{obl}, \mathrm{sg}, \mathrm{fem}\}$ and $\{\mathrm{ins}, \mathrm{sg}, \mathrm{fem}\}$, respectively). Instrumental forms of non-feminine nouns, of class $\mathrm{A}$ as well as of class B, show the plain oblique

\footnotetext{
${ }^{52}$ For discussion, see Jakobson (1958, sections 4.4, 4.8), Stankiewicz (1968, 26), Franks $(1995,51 f$.$) . The terms "short" and "long" as used here (cf. sec. 2.6, supra) correspond to$ Jakobson's "monophonemic" and "polyphonemic", respectively.
} 
ending -om, categorized as $\{\mathrm{obl}, \mathrm{sg}$, non-fem $\}$, thus the non-feminine counterpart of feminine -oj. Interestingly, with pronouns and adjectives, the S4ending (-om) does not occur in the instrumental case (but in the prepositional case). Competition in underspecified paradigms (controlled by the principle of specificity) results in giving this plain oblique form its seeming ambiguity, functioning as it does as a prepositional ending with non-nouns and as an instrumental ending with nouns. Using underspecification the present approach reveals the functional unity of the ending -om, which could not be captured in traditional accounts; similarly for the S8-ending (-oj).

A slight variation is found in the feminine of class B. First, the S8-ending is not used in class B. Second, in Russian declensional endings the first segment is, as a rule, a vowel. However, when applied to class B nouns, in extra long (three-phoneme) endings the initial vowel may drop, infrequently in the plural but always in the singular. ${ }^{53}$ Consequently, the S9-ending comes in two variants, a three-phoneme variant in class $\mathrm{A}$ and a two-phoneme variant in class $\mathrm{B}$, and thus may be given as $-[V] j u .^{54}$

The rest of the oblique singular noun endings, which are not taken from the general inventory, remain to be categorized. In Table 7, boxes illustrate differences in specificity to be captured. The ending $-i$ occurs in all of the cases under consideration - prepositional (I/II), dative, and genitive (I/II); within this domain, it occurs in both the feminine and in the non-feminine, and moreover, it applies to class A nouns as well as to class B nouns. Thus, $-i$ is to be characterized simply as an unspecific marker for oblique cases, excepting, of course, the instrumental. From the domain potentially covered by $-i$, subdomains are cut out, as it were, and are filled by endings that are more specific. The ending $-e$ in particular is restricted to class A and is not allowed in the genitive (I/II); $-a$ on the other hand is straightforwardly characterized as a genitive (I/II) ending that is restricted to non-feminine class A nouns. Both of these endings give way to $-u$ in forms of nouns that allow special dative and partitive (genitive II) forms. Finally, some nouns (mostly inanimate masculines of class A) exhibit special locative (prepositional II) forms, whose endings differ from the corresponding dative endings by always being stressed. ${ }^{55}$

\footnotetext{
${ }^{53} \mathrm{~A}$ few class B nouns show $-m^{\prime} i$ (instead of $\left.-a m^{\prime} i\right)$ in the dative plural; see Comrie, Stone \& Polinsky $(1996,132)$.

${ }^{54}$ Cf. also Stankiewicz $(1968,25)$, who writes “-\#ju” for the shorter variant, with "\#” for a "zero unit"; similarly Kortlandt $(1974,58)$.

${ }^{55}$ Generally, endings may be stressed or unstressed depending on the noun's stress pattern.
} 
Combinatorial configurations of endings from the set under discussion appear to maintain a non-random pattern. Within the oblique singular domain there are four ways of selecting from the set of more specific endings (-e, $-a$, $-u$ ) that contrast with the rather unspecific ending $-i$, as illustrated in (13); for the sake of clarity, secondary cases have been omitted.

(13) Selection from the set of oblique singular endings $-i,-e,-a,-u$
(i) $-i$
(type $\mathrm{KOST}^{\prime}$, dec. III)
(ii) $-i-e$
(type GORA, dec. II)
(iii) $--e-a$
(personal pronouns; cf. sec. 3.8)
(iv) $-\quad-e-a-u$
(type ZAKON, dec. I)

Starting from the minimal inventory, which includes only the least specific of these endings, the scale from (13i) to (13iv) shows an increase in the number and specificity of markers. In the last two combinations, (iii) and (iv), application of $-i$ is suppressed, since its entire domain is occupied by more specific endings. In this subsystem, all of the Russian vowels find use as morphological markers, leaving out only the default ending vowel $o$. A hierarchy $i>e>a>u$ emerges that is adhered to as the system expands (or shrinks). As this order, corresponding as it does to increasing specificity of case marking, mirrors an ordering of vowels along the front-back dimension of the vowel space, diagrammatic iconicity may again be involved. ${ }^{56}$

\subsection{Revised System of Case Classifications}

Among noun declensions, class A non-feminine nouns show the most elaborated paradigms. In the unmarked gender, the non-neuter, one subclass even adds extra differentiations ("secondary cases") that are foreign to the rest of

Fixed stress is indicated by an acute on the vowel of loc endings. Locatives in $-i$, found with a restricted group of lexically marked dec. III feminines, will be neglected in the following for simplicity of presentation. Cf. Garde (1980, 187, § 267), Stankiewicz $(1968,38)$, Comrie, Stone \& Polinsky $(1996,125)$.

56 "Strength" of vowels (defined as increasing with distance from the point vowel $i$ in the vowel space) has been repeatedly alluded to as a possible basis for iconic patterns, especially with reference to Indo-European ablaut and to the vocalism of deictics; cf. Plank (1979, sec. 5). A correlation between vowel strength and functional markedness of inflectional endings, in particular, is assumed for Greek, a language where vowel strength is an independently established factor in sandhi rules, in Warburton (1973). However, Shapiro (1969), Plank (1979, sec. 4), and Müller (this volume) suggest that in Russian, increasing sonority (of vowels) may correspond to decreasing functional markedness. 
the system. Feminines show less differentiation and hence less specific markers. Finally, in unexceptional class B nouns all distinctions within the oblique singular are wanting (apart from the instrumental). It appears that the degree of syncretism (put differently, the degree of formal differentiation) is not distributed at random but instead reflects differences in the status of declensions, namely, differences to be specified in terms of declension class markedness. ${ }^{57}$ I suggest that such non-random patterns of syncretism should be reflected in a proper analysis of the case system, and the means to do this is to put more structure into the system of case classifications.

As has been observed above, the data suggest a major division between instrumental case and non-instrumental cases, while the major dividing line within non-instrumental cases is between genitive (I/II) and non-genitive; the latter domain may split up into dative and prepositional, and, as a further extension, forms of secondary cases may be distinguished. This series of divisions may be regarded as constituting a hierarchical system of classifications as established by the classification tree in (14), which represents the complete system of case classifications of Russian.

(14)

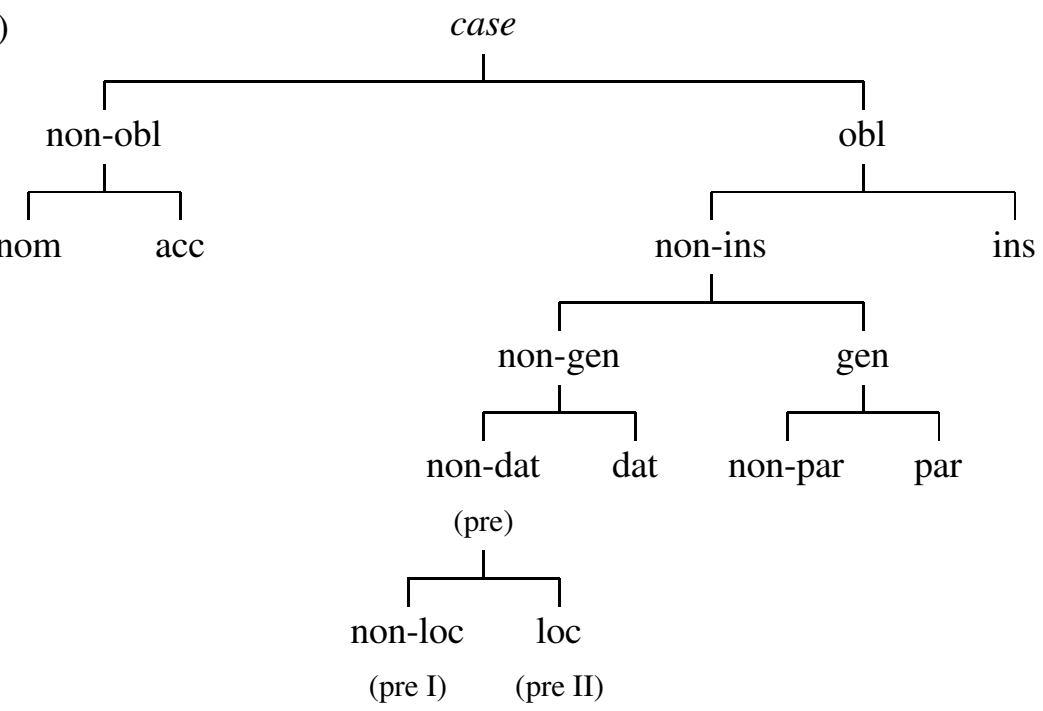

The tree is to be understood as indicated for (2) and (3). Terminal categories are subsets of superordinate categories, i.e., of categories higher up in the tree;

\footnotetext{
${ }^{57}$ On declension class markedness, see Wurzel (1989). Note that it is only the unmarked declension type (IA) that allows DOM in the singular.
} 
any superordinate category equals the union of the categories it dominates (e.g., obl = non-ins $\cup$ ins; likewise, non-gen $=$ non-dat $\cup$ dat). ${ }^{58}$ Alternative case names have been given in parentheses, for convenience.

As compared to (2), the subdivision of non-obl has been left unmodified in (14). However, in colloquial style personal names following dec. II may allow vocative singular forms (without endings), distinct from nominative forms (in $-a$ ), whereas the nominative covers the vocative function elsewhere. Hence, a further subdivision of the non-oblique domain may be called for. The possibility may be considered that non-obl splits into non-acc and acc, and non-acc in its turn into non-nom and nom, where non-nom $=$ voc (vocative) ${ }^{59}$

\subsection{Categorizations of Oblique Singular Noun Endings}

Categorizations of long endings, which appear in the instrumental singular of nouns, have been given above. In addition, categorizations for short oblique singular noun endings may now be specified, given the system of case classifications presented in (14). For two class A noun endings suitable categorizations are already available, namely, $\mathrm{S} 6$ for the dative ending $-u$ and $\mathrm{S} 7$ for the genitive ending $-a$ (cf. Table 3); these are restricted to the non-fem as are their long non-noun counterparts, $-V m u$ and $-V v o$.

Categorizations for $-i$ and $-e$ are added as S10 and S11 in Table 8. In keeping with the above discussion, $-i$ is categorized as a non-instrumental singular ending (S10). Thus, $-i$ may occur in any oblique case, excepting the instrumental, provided no more specific oblique case ending takes priority. The S10-ending is the only ending in this group that applies to both class A and class B nouns; the remaining, more specific ones are restricted to class A nouns.

Ending $-e$ is categorized as non-genitive singular (S11). Since, by (14), non-gen $=$ non-loc $\cup$ loc $\cup$ dat, the S11-ending may occur in the prepositional

\footnotetext{
${ }^{58}$ Categories of the type non- $X$ are sister categories to categories of the type $X$; hence, a category like non-dat does not cover all those case forms that happen not to be dative forms (say, nominative or accusative forms). Rather, non-dat (= pre) covers all and only non-loc forms (prepositional I forms) and loc forms (prepositional II forms), as indicated in (14); i.e., non-dat $=$ non-loc $\cup$ loc. Recall that non-loc $=$ pre I, loc = pre II; moreover, non-par $=$ gen I, par $=$ gen II, and pre $=$ pre I $\cup$ pre II.

${ }^{59}$ The vocative case in Russian, if assumed at all, surely has a peripheral status (cf. Garde $(1980,136 / 148 f),. \S \S 181,203)$. Nonetheless, if only for reasons of comparability, one would want to indicate the place in the system of cases that the vocative should occupy if present (as is done in the text).
} 
I (non-locative), the prepositional II (locative) and the dative, provided no more specific oblique case ending takes priority.

S12 and S13 provide endings for the partitive (genitive II) and the locative (prepositional II), respectively; S12- and S13-endings are restricted to lexically marked subclasses of the masculine. As noted above (cf. section 2.3), there are no special pre (non-dat) forms though there are special pre II (loc) forms.

Table 8: Additional categorizations of noun endings: oblique singular

\begin{tabular}{|c|c|c|c|c|c|c|}
\hline case & number & gender & ending & $\#$ & $\mathrm{~A}$ & $\mathrm{~B}$ \\
\hline \hline non-ins & $\mathrm{sg}$ & - & $-i$ & $\mathrm{~S} 10$ & + & + \\
\hline non-gen & $\mathrm{sg}$ & - & $-e$ & $\mathrm{~S} 11$ & + & - \\
\hline \hline par & $\mathrm{sg}$ & non-neut & $-u$ & $\mathrm{~S} 12$ & \pm & - \\
\hline loc & $\mathrm{sg}$ & non-neut & $-u$ & $\mathrm{~S} 13$ & \pm & - \\
\hline
\end{tabular}

Class A nouns (A), class B nouns (B),

,-+ : (non-)applicable, \pm : applicable, lex. marked subclass only

\subsection{Plural Noun Endings}

All of the general plural endings (listed in Table 3) are applicable equally to nouns of both class A and class B. (This implies, of course, that the distinction of declension classes is largely eliminated in the plural.) The only modification concerns the initial vowel of oblique plural endings, which is $a$ for nouns. ${ }^{60}$ However, there are two noun-specific additions to the declensional system in the plural.

First, noun declension adds special non-oblique neuter forms in $-a$, thus transferring from the singular, as it were, the option of having a special neuter non-oblique form - a plural counterpart of the S1-ending, listed under P2 in Table 9. This ending, too, applies to both major noun classes. ${ }^{61}$

Second, the general inventory does not countenance special genitive plu-

\footnotetext{
${ }^{60}$ The initial vowel is missing in a few items in the instrumental plural, cf. note 53 , supra. In lexically marked subclasses of nouns the unspecific plural ending (P1) also shows, optionally or obligatorily, the vowel $a$; cf. Stankiewicz $(1968,41-46$; 49-60) and Comrie, Stone \& Polinsky (1996, 127-129) for details.

${ }^{61} \mathrm{P} 2$ cuts into the domain of P1, but a subclass of neuters do not accept the P2-form; cf.
} 
ral forms (hence with non-nouns the plain oblique plural form takes over). Within noun declension, this gap is filled (see P6 in Table 9). Genitive plurals show two different endings (or two versions of one ending), viz., - $e j$ or $-o v$, the distribution of which is conditioned by phonological properties of stems. ${ }^{62}$ As a third possibility, genitive plural noun forms may fail to show an ending. However, as a rule, genitive plural forms are kept distinct even with nouns that do not command special genitive plural endings.

Table 9: Categorizations of noun endings: plural

\begin{tabular}{|c|c|c|c|c|c|c|}
\hline case & number & gender & ending & $\#$ & $\mathrm{~A}$ & $\mathrm{~B}$ \\
\hline \hline- & $\mathrm{pl}$ & - & $-i$ & $\mathrm{P} 1$ & + & + \\
\hline non-obl & $\mathrm{pl}$ & neut & $-a$ & $\mathrm{P} 2$ & + & + \\
\hline \hline obl & $\mathrm{pl}$ & - & $-a x$ & $\mathrm{P} 3$ & + & + \\
\hline ins & $\mathrm{pl}$ & - & $-a m^{\prime} i$ & $\mathrm{P} 4$ & + & + \\
\hline dat & $\mathrm{pl}$ & - & $-a m$ & $\mathrm{P} 5$ & + & + \\
\hline gen & $\mathrm{pl}$ & - & $-(e j \sim o v)$ & $\mathrm{P} 6$ & + & + \\
\hline
\end{tabular}

"()": drops, subject to the No-Homonymy Condition

Appearance or non-appearance of genitive plural endings does not relate in a simple way to noun declensions as established above, although it is true that nouns of the neuter declension types (such as VINO and VREMJA) usually do not show endings in the genitive plural. The principle that determines the presence or absence of endings in the genitive plural is orthogonal to divisions of declension and gender. Generally speaking, genitive plural forms show an ending only if absence of the ending would regularly result in a homonymy with some other form of the same noun. This pertains to nominative or accusative singular forms, since these may also lack endings (cf. Table 5). Apart from endings on nominative/accusative singular forms, a range of factors are active in rendering genitive plural endings "superfluous", including stress shift and stem alternations. ${ }^{63}$

Stankiewicz $(1968,47)$. In this case, the unspecific plural form (P1) takes over once more. Clearly, $-i$ is the "default ending" in the nominative plural (Stump 1993, 474).

${ }^{62}$ The ending - $e j$ appears after soft and "hushing" consonants, - $o v$ after other consonants and $/ \mathrm{j} /$ (Jakobson (1958, sec. 4.5)); in consequence, due to their stem forms, class B nouns allow only $-e j$, not $-o v$.

${ }^{63}$ This regularity has been pointed out by Jakobson $(1939,1957,1958)$; for discussion, see also Johnston (1997, sec. 2.4.2), who notes that the interplay of forms with and without 
As for the standard declensions, nouns in declension IA (e.g., ZAKON) do not exhibit endings in the nominative singular but do show genitive plural endings; the remaining types of class A nouns (from declensions IB and II), which do have endings in the nominative singular (cf. VINO, GORA), with few exceptions do not accept genitive plural endings. ${ }^{64}$ On the other hand, class B nouns do not exhibit endings in the non-oblique singular. Accordingly, they employ genitive plural endings (cf. putej of $\mathrm{PUT}^{\prime}$, kostej of KOST'), excepting the small group of neuters (such as VREMJA). Furthermore, nouns of the latter type show a stem alternation that prevents homonymy anyway, and here again genitive plural forms do not adopt the ending (cf. vremja, non-oblique singular, vs. vremën, genitive plural) ${ }^{65}$ From a synchronic point of view, this harmonization of morphological marking within paradigms can be considered remarkable, since it is not derivable from competition and specificity.

In short, the notation $-(e j \sim o v)$ in the P6-entry in Table 9 indicates that genitive plural forms of nouns may show one of two endings, $-e j$ or -ov, selected according to the phonological form of the stem. Parentheses indicate that genitive plural forms may regularly lack endings, application of endings being, in this case, conditional on the described strategy of homonymy avoidance (the "No-Homonymy Condition"). ${ }^{6}$

endings may provide "some evidence for the reality of paradigms" (op. cit., p. 107). There are nouns like RAZ ('time') that do not show endings either in the nominative singular or in the genitive plural, but these are usually restricted to constructions (in French, "syntagmes") that dissolve the homonymy (Jakobson (1939, sec. I)); this is a property of nouns "belonging to certain lexical fields that are commonly used in quantitative constructions" (Timberlake $(2004,138))$.

${ }^{64}$ Some neuter and feminine class A soft stem nouns adopt the - $e j$ ending (but no feminine shows the -ov ending, Jakobson (1958)); for further details, see Stankiewicz $(1968,50-56)$ and Garde (1980, §§ 202, 215, 239), and cf. Shapiro (1971). For recent developments, see Comrie, Stone \& Polinsky (1996, 129-131).

${ }^{65} \mathrm{By}$ other analyses, these neuters do have the ending - $o$ in the non-oblique singular; cf. note 50, supra. On stem alternations, see Stankiewicz (1968, esp. on the VREMJA-type, p. 60f.).

${ }^{66}$ Further analysis and interpretation of this obvious example (of the more general phenomenon) of homonymy avoidance is beyond the scope of the present study (but see Hentschel \& Menzel (2002)); its theoretical implications remain to be investigated. We may note, however, that it is not without parallels outside Russian; consider, e.g., the strong tendency to avoid genitives "die als solche nicht erkennbar sind" ('which are not recognizable as such'; Paul $(1919,328)$, note 1), which is well known from German. 


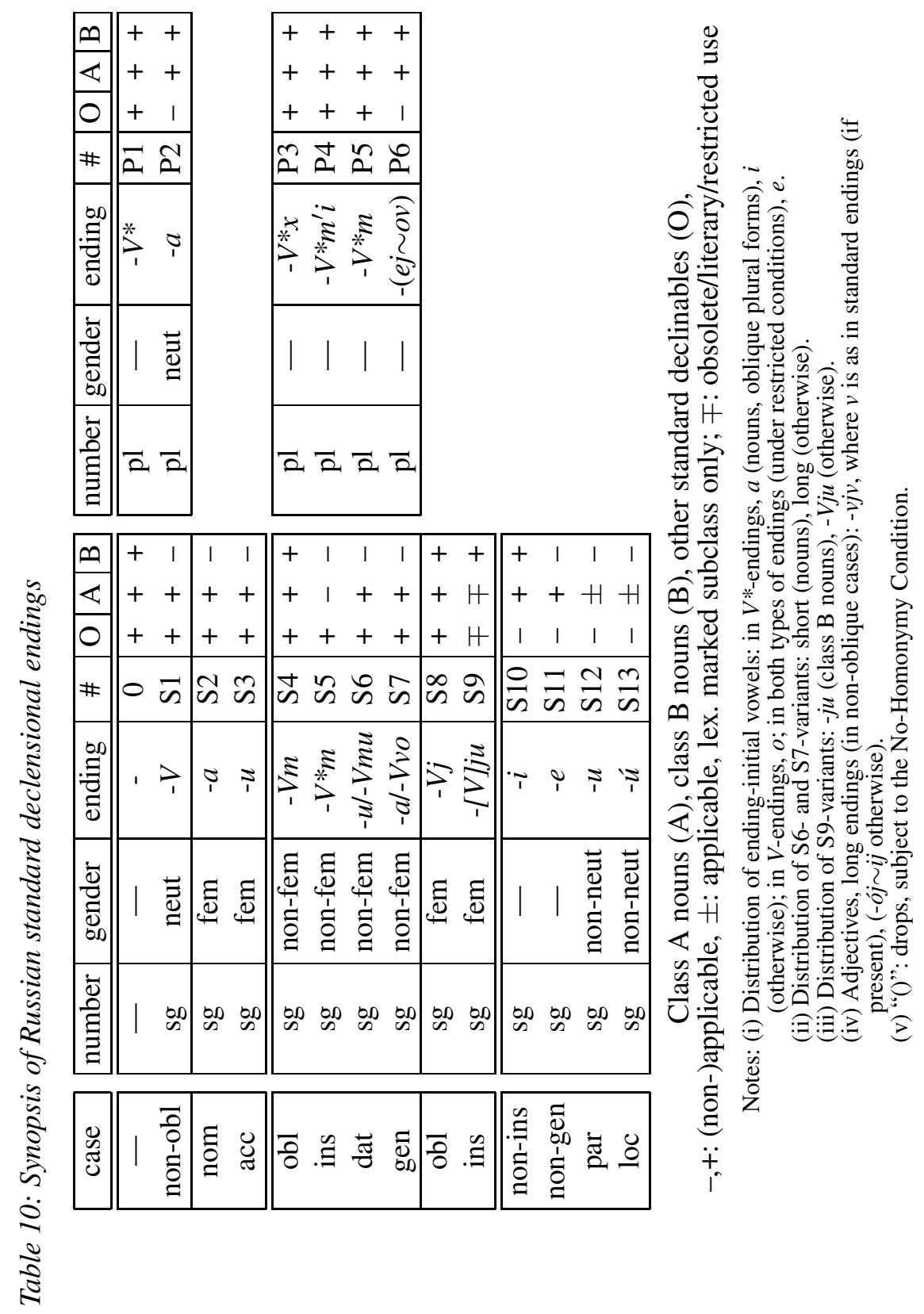




\subsection{Underspecified Noun Paradigms}

In the above, endings of nouns have been discussed and assigned categorizations. Overall, the set of endings that had been established for the pronoun ЁтOT in section 2 has been extended only moderately. Nouns add a neuter plural, fill the empty slot for the genitive plural, and, most importantly, add a special subsystem of non-instrumental singular endings.

Combining the analyses of pronominal, adjectival, and nominal declensions, which have been proposed above (and which have been presented in Tables 3, 4, 6, 8, and 9), we may now identify an integrated assemblage of endings (or form categories) and categorizations that answers for the totality of regular declension. Table 10 provides a synopsis. Notational conventions are as before but are specified in the legend where appropriate; names of $V^{*}$-endings have to be reinterpreted as indicated in order to account for ending-initial vowels of nouns. Thus, an overall inventory of form-function pairs is established that make up the basis of regular declensions, providing the building blocks for the various declensional paradigms found in Russian. Differences between paradigms are due to different selections possible from the overall set, which are also specified in Table 10. Categorizations assigned to endings are invariant across paradigms, but of course, the actual range of application (as determined in terms of specific case-number-gender combinations) allowed by some given ending depends on which competing endings qualify for inclusion in the same paradigm.

Table 10 may be read as a recipe for deriving declensions, hence, for deriving paradigms. The declension of class A masculine nouns serves to illustrate: All ending-categorization pairs are selected that are marked by a plus in the A column and that are not restricted to feminines or to neuters according to the gender column. Other declensions are derived analogously. In this manner, we arrive at the paradigm schemes in Table 11 and Table 12, below. (Actual ending-initial vowels have been specified. Endings of secondary cases have not been included; similarly, for class A feminines, the obsolete S9-ending has been ignored. Genitive-accusatives of animate nouns would have to be derived as explained in section 2.9.)

In Table 11, blocks of singular endings of different declensions have been put side by side for better comparability; likewise for the plural. Rows in blocks specify case. There is no extrinsic ordering of endings, but for perspicuity, the vertical order has been arranged so as to correlate, first, with the 
Table 11: Paradigm schemes: class A nouns

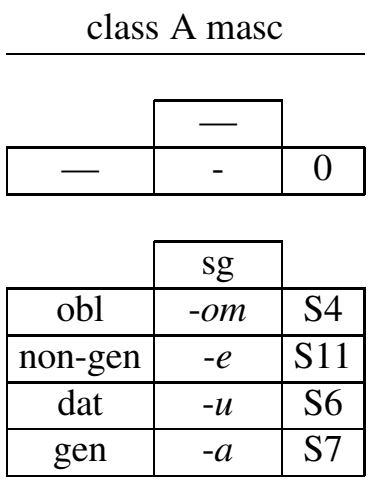

\begin{tabular}{|c|c|c|}
\hline & sg & \\
\hline non-obl & $-O$ & $\mathrm{~S} 1$ \\
\hline obl & -om & S4 \\
\hline non-gen & $-e$ & $\overline{\mathrm{S} 11}$ \\
\hline dat & $-u$ & S6 \\
\hline gen & $-a$ & S7 \\
\hline
\end{tabular}

\begin{tabular}{|c|c|c|}
\cline { 2 - 3 } \multicolumn{1}{c|}{} & sg & \multicolumn{1}{c|}{} \\
\hline nom & $-a$ & $\mathrm{~S} 2$ \\
\hline acc & $-u$ & $\mathrm{~S} 3$ \\
\hline obl & $-o j$ & $\mathrm{~S} 8$ \\
\hline non-ins & $-i$ & $\mathrm{~S} 10$ \\
\hline non-gen & $-e$ & $\mathrm{~S} 11$ \\
\hline
\end{tabular}

\begin{tabular}{|c|c|c|}
\cline { 2 - 3 } \multicolumn{1}{c|}{} & $\mathrm{p} 1$ & \multicolumn{1}{c}{} \\
\hline- & $-i$ & $\mathrm{P} 1$ \\
\hline obl & $-a x$ & $\mathrm{P} 3$ \\
\hline ins & $-a m^{\prime} i$ & $\mathrm{P} 4$ \\
\hline dat & $-a m$ & $\mathrm{P} 5$ \\
\hline gen & $-e j \sim o v$ & $\mathrm{P} 6$ \\
\hline
\end{tabular}

\begin{tabular}{|c|c|c|}
\cline { 2 - 3 } \multicolumn{1}{c|}{} & $\mathrm{pl}$ & \multicolumn{1}{c|}{} \\
\hline non-obl & $-a$ & $\mathrm{P} 2$ \\
\hline obl & $-a x$ & $\mathrm{P} 3$ \\
\hline ins & $-a m^{\prime} i$ & $\mathrm{P} 4$ \\
\hline dat & $-a m$ & $\mathrm{P} 5$ \\
\hline gen & - & P6 \\
\hline
\end{tabular}

\begin{tabular}{|c|c|c|}
\cline { 2 - 2 } \multicolumn{1}{c|}{} & $\mathrm{pl}$ & \multicolumn{1}{c|}{} \\
\hline- & $-i$ & $\mathrm{P} 1$ \\
\hline obl & $-a x$ & $\mathrm{P} 3$ \\
\hline ins & $-a m^{\prime} i$ & $\mathrm{P} 4$ \\
\hline dat & $-a m$ & $\mathrm{P} 5$ \\
\hline gen & - & $\mathrm{P} 6$ \\
\hline
\end{tabular}

non-obl/obl distinction and, second, with increasing specificity where possible.

Forms without endings appear in the genitive plural where specified and whenever no ending is applicable, for instance, in non-oblique singular cases of masculine class A nouns. In the latter case, the respective forms are assigned the empty categorization.

Endings that are applicable in principle may get no chance to apply, their domain being "bled" by endings that are more specific. For example, the noninstrumental S10-ending (- $i$ ) applies to both class A and class B nouns, and to both non-feminine and feminine nouns. Nevertheless, it does not appear with class A non-feminines, since for these nouns the domain of non-instrumental cases is fully covered by more specific endings (S6, S7, S11). Similarly, class A neuter and feminine nouns do not show forms that are assigned the empty categorization.

Table 12 provides paradigm schemes for class B nouns. As has been pointed out, feminines (like $\mathrm{KOST}^{\prime}$ ) constitute the major type of class B nouns; neuters declined like VREMJA, a small group of nouns which are here subsumed under class B, show stem alternation between non-oblique singu- 
lar forms and the rest of the paradigm and are, presumably mainly for this reason, often not included in dec. III. Note, however, that no changes whatsoever in the overall analysis would be called for if we decided to ignore class B neuters. Indeed, given the overall analysis, the points where their declension deviates from the declension of class B feminines are predictable. Relevant observations are the following: (i) The S9-ending cannot appear, since it is restricted to the feminine (the plain oblique non-feminine ending, S4, takes over). (ii) Regularly declined neuters show $-a(\mathrm{P} 2)$ in non-oblique plurals. (iii) By the general regularity for the genitive plural (P6), forms without endings are expected. It is exactly at these positions that the inventories of class $B$ neuter and feminine endings differ. (Similarly, nothing would be gained by neglecting the only masculine class B noun, PUT $^{\prime}$; again, the structure of its paradigm follows from the overall analysis without added stipulations.)

Table 12: Paradigm schemes: class B nouns

\begin{tabular}{|c|c|c|c|c|c|c|c|c|}
\hline \multicolumn{3}{|c|}{ class B masc } & \multicolumn{3}{|c|}{ class B neut } & \multicolumn{3}{|c|}{ class B fem } \\
\hline & - & & & - & & & - & \\
\hline - & - & 0 & - & - & 0 & - & - & 0 \\
\hline & $\mathrm{sg}$ & & & sg & & & sg & \\
\hline obl & -om & S4 & obl & -om & S4 & non-ins & $-i$ & S10 \\
\hline non-ins & $-i$ & S10 & non-ins & $-i$ & S10 & ins & $-j u$ & S9 \\
\hline & $\mathrm{pl}$ & & & $\mathrm{pl}$ & & & $\mathrm{pl}$ & \\
\hline - & $-i$ & P1 & non-obl & $-a$ & P2 & - & $-i$ & P1 \\
\hline obl & $-a x$ & P3 & obl & $-a x$ & $\mathrm{P} 3$ & obl & $-a x$ & $\mathrm{P} 3$ \\
\hline ins & $-a m^{\prime} i$ & P4 & ins & $-a m^{\prime} i$ & P4 & ins & $-a m^{\prime} i$ & P4 \\
\hline dat & $-a m$ & P5 & dat & $-a m$ & P5 & dat & $-a m$ & P5 \\
\hline gen & $-e j$ & P6 & gen & - & P6 & gen & $-e j$ & P6 \\
\hline
\end{tabular}

It can be read off Table 12 that, say, class B feminine nouns exhibit two different singular endings (categorized for case as non-instrumental and instrumental, respectively), which cover oblique cases, while singular forms of non-oblique cases lack endings. On this basis, underspecified paradigms for particular noun lexemes are easily derived. From these, in turn, fully specified paradigms may be derived by filling the cells of a full array of case-number 
combinations with forms from underspecified paradigms abiding by the principle of specificity. This is illustrated for the singular subparadigm of KOST' ('bone'), a class B feminine noun, in Table 13. ${ }^{67}$

\section{Table 13: Singular subparadigm of KOST' ('bone')}

underspecified

\begin{tabular}{|c|c|c|}
\hline case & number & form \\
\hline 一 & - & kost' \\
\hline non-ins & sg & kosti \\
\hline ins & sg & $k_{o s t}{ }^{\prime} j u$ \\
\hline
\end{tabular}

fully specified

\begin{tabular}{|c|c|c|}
\hline case & number & form \\
\hline nom & sg & kost $^{\prime}$ \\
\hline acc & sg & kost $^{\prime}$ \\
\hline gen & sg & kosti $^{\prime}$ \\
\hline pre & sg & kosti \\
\hline dat & sg & kosti $^{\prime}$ \\
\hline ins & sg & kost $^{\prime} j u$ \\
\hline
\end{tabular}

\subsection{Additional Paradigms}

Irregular formations and minor subregularities, as described in reference grammars, are well beyond the scope of this essay. However, it is worthwhile noting that paradigms which do not conform to standard patterns may still take their endings from the overall inventory of form-function pairs.

Surnames like Tolstoj follow the standard adjectival declension. Another type of surnames (like Čexov or Puškin) follows the pronominal declension (cf. Table 3), and as regards feminine and plural forms, there are no aberrations. However, in the masculine singular, this type employs in addition, and gives priority to, the extra set of short oblique case endings known from regular masculine nouns, as given in (13iv) - viz., - $e$ (S11), - $a$ (S7), - $u$ (S6). In conformance with their categorizations and the principle of specificity, these endings cover the prepositional, genitive, and dative, respectively; only the instrumental is left to take on the expected pronominal ending (-im, S5). It may be remarked that, while the selection made from the inventory of endings is not as in standard declensions, categorizations apply as usual. ${ }^{68}$

\footnotetext{
${ }^{67}$ As a set, the underspecified paradigm of $\operatorname{KosT}^{\prime}$ is identified as $\operatorname{KOST}^{\prime}{ }^{\mathrm{UP}}=\left\{\left\langle\right.\right.$ kost $\left.^{\prime},\{\}\right\rangle$, $\langle$ kosti, \{non-ins, sg $\}\rangle,\left\langle\right.$ kost $^{\prime} j u,\{$ ins, sg $\left.\}\right\rangle,\langle$ kosti, $\{\mathrm{pl}\}\rangle,\langle$ kostjax, $\{$ obl, pl $\}\rangle,\langle$ kostjami, $\{$ ins, $\mathrm{pl}\}\rangle,\langle$ kostjam, $\{$ dat, $\mathrm{pl}\}\rangle,\langle$ kostej, $\{$ gen, $\mathrm{pl}\}\rangle\}$.

${ }^{68}$ For further details, see Garde (1980, 200-203, §§ 291-295), Timberlake (2004, 153-158) .
} 
Non-gendered personal pronouns, viz., JA/MY (first person singular/plural) and TY/VY (second person singular/plural), present another case in point. ${ }^{69}$ In the singular, these pronouns, being genderless, mix endings that are, as a rule, restricted to either non-feminines or feminines. However, the endings that are employed are familiar ones, having their usual case and number values: $-a$ in the genitive (\{gen, sg $\}$; cf. S7), $-e$ in the prepositional and in the dative (\{non-gen, sg \}; cf. S11), and -oj (or, alternatively, -oju) in the instrumental (\{obl, sg $\}$ or $\{$ ins, sg $\}$; cf. S8 and S9, respectively). Nominative singular forms $(j a, t y)$ have no endings, and accusative forms equal genitive forms (both in the singular and in the plural). Selection of endings from the overall inventory is once more idiosyncratic; but apart from irrelevance of gender specifications, categorizations are as given above. As for the plural, the paradigmatic pattern follows the pronominal model (which does not include P2- and P6-endings; cf. Table 3) whereas the composition of plural forms follows the nominal model (cf. Table 10), the endings being $-i$ (P1), -as (P3), - $a m^{\prime} i$ (P4), -am (P5); it is only the consonant of the P3-ending that deviates.

Finally, indeclinable nouns provide a limiting case. Indeclinable nouns are, of course, nouns that do not accept any endings, hence nouns that have one and only one form for all case-number combinations. Even if underspecification were to be avoided in general, here at least non-differentiation of forms must be acknowledged. Presumably, no respectable grammar includes full paradigmatic tables for indeclinables. No problems arise for the present approach. For an indeclinable noun like PONI ('pony') an underspecified paradigm is assumed that contains exactly one form, viz., poni, which is assigned the empty categorization. Because the categorization is empty, the make-up of the form, which has no ending, is as expected. ${ }^{70}$

As for possessive adjectives, short S6- and S7-forms, sometimes listed in reference grammars, are judged to be no longer normal (Comrie, Stone \& Polinsky $(1996,134)$ ).

${ }^{69}$ Endings are assumed as in Jakobson (1958); cf. also Garde (1980, 252f., §§ 389, 393). The reflexive SEBJA takes its endings from the same set.

${ }^{70}$ Hence, $\mathrm{PONI}{ }^{\mathrm{UP}}=\{\langle$ poni, \{\}$\rangle\}$. For various groups of indeclinables (loanwords, placenames, acronyms, etc.), see Garde (1980, 197-200, §§ 285-290). 


\section{Types of Syncretisms}

Whereas the overall picture of Russian declension that has emerged in the above differs from that in standard reference grammars, the means for dealing with syncretisms are quite traditional. First, most grammars recognize, and account for, underdifferentiation of forms (or "neutralization") in the arrangement of paradigmatic tables to some degree. In particular, it is a matter of course that paradigmatic tables for pronouns and adjectives, which show three gender-specific columns in the singular block, lack such differentiation in the plural. While traditional grammar takes advantage of what in recent terminology would be called underspecification in its treatment of nondifferentiation of gender, it does so only sporadically in dealing with case syncretisms. A number of modern approaches, including the present one, deviate by consistent application of underspecification.

Second, many reference grammars of Russian account for accusativegenitives not by filling the accusative slot in paradigmatic tables by inflectional forms, but by directing the reader to the nominative and/or genitive case whenever appropriate. ${ }^{71}$ This technique of referral, too, has been adopted above, using genitive-accusative equations. However, it has been restricted to genitive-accusative homonymies, as non-differentiation between nominative and accusative forms (caused by absence of special accusative forms) requires no extra handling in an approach that makes thoroughgoing use of underspecification.

The distinction of two types of syncretism, implicit in traditional descriptions of Russian, is justified by notable differences between the respective phenomena. Moreover, it fits perfectly well into a general typology of syncretisms. ${ }^{72}$ However, it has been proposed repeatedly in the literature (i) to

\footnotetext{
${ }^{71}$ See, e.g., "N. or G." in Unbegaun (1957); similarly in most reference grammars. In more formally oriented, rule-based treatments this technique has been taken over under the name of prediction rules in Perlmutter \& Orešnik (1973) and Corbett $(1980 ; 1981)$ or rules of referral (Stump (1993), following Zwicky (1985)); it is subsumed under readjustment rules in Halle (1994). Corbett (1980) combines rules of referral (feature-change rules, prediction rules) with what would be in more recent terminology rules of impoverishment (copying restriction for the feature [+animate]); cf. Halle \& Marantz (1993).

${ }^{72} \mathrm{Cf}$. Baerman, Brown \& Corbett (2002), who distinguish three types of syncretisms that are "common enough cross-linguistically" (op. cit., p. 24) to call for inclusion in a typology of syncretisms: (i) syncretism of core cases (viz., nominative and accusative in an accusative language, i.e., non-oblique cases), (ii) syncretism of the marked core case and an oblique case, (iii) (total) syncretism of oblique cases. All of these types are instantiated in Russian, plus a
} 
treat genitive-accusatives in terms of underspecification, not by referral and (ii) to extend referral to a much wider range of phenomena. Questions regarding a general taxonomy of syncretisms are outside the scope of this paper. Yet, it may be in order to end with a brief comparison of the two types of syncretisms found, based on instances that have been analyzed above.

To establish a categorization that is underspecified with respect to case means to delimit a domain of application for some ending that covers more than a single terminal case category. Nevertheless, the total domain thus determined will be covered by the ending in question only if there are no applicable competing endings with more specific categorizations. Typically, competition may cut into the domain limited by the underspecified categorization; as a result, unspecific endings may be distributed over seemingly disparate ranges of cells of paradigms. It is a virtue of underspecification that it helps us to detect what constitutes the functional unity of endings under such circumstances. Various cases of this type have come to the fore in the above, among them the intriguing interplay of endings (presented in Table 7) that is found in the domain of oblique singular noun endings. An unmarked (or rather relatively unmarked) ending (here -i) gives way to more specific ones (like $-e$ and $-a$ ), while the latter's domains may in turn be perforated, as it were, by competing endings that are assigned even more specific categorizations.

If an unspecific ending is not given an underspecified categorization, we are often left with a dismembered field of application that, if it were to be covered directly, might well require a multiplicity of statements (or rules) of exponence and referral. It would appear that attempts at analyzing distributions of cascading "overrides" between endings in terms of referrals must lead to unnecessarily complicated and presumably unrevealing descriptions. ${ }^{73}$

The pattern of syncretisms found with animate genitive-accusatives is of another kind. While underspecification as applied above reduces the num-

fourth type, also recognized by Baerman, Brown, and Corbett, viz., syncretism of some, but not all, non-core cases (= oblique cases), which is, they note, rare outside Indo-European.

${ }^{73}$ Cf. Fraser \& Corbett (1995), who deal with the distribution of $-i$ in the domain under discussion by introducing $-i$ as the genitive singular ending of dec. II, adding to this "rule of exponence" three equations, which in their (DATR) framework function as analogues of rules of referral, informally to be rephrased as follows: (i) In dec. III, the gen sg ending is the same as in dec. II. (ii) In dec. III, the dat sg ending is the same as the gen sg ending. (iii) In dec. III, the pre sg ending is the same as the dat sg ending. For a conception of rules of exponence as defaults that may be overridden, see Zwicky (1985). 
ber of ending-categorization pairs and uncovers functional unity underlying seemingly disorganized distributions of endings, any treatment of genitiveaccusative syncretism with animates in terms of underspecification would result in an increase in the number of ending-categorization pairs. ${ }^{74}$

Table 14: Animate and inanimate accusatives.

(i) masculine pronoun forms, (ii) forms of masculine nouns

(i)

\begin{tabular}{|c|c|}
\hline \multicolumn{2}{|c|}{ ÈTOT } \\
\hline inanim & anim \\
\hline ètot & ètot \\
\hline ètot & ètogo \\
\hline ètogo & ètogo \\
\hline
\end{tabular}

(ii)

\begin{tabular}{|c|c|}
\multicolumn{1}{c}{ STOL } & \multicolumn{1}{l}{ SLON } \\
\hline inanim & anim \\
\hline stol & slon \\
\hline stol & slon- $a$ \\
\hline stol- $a$ & slon- $a$ \\
\hline
\end{tabular}

Consider the distribution of the forms ètot and ètogo over the cells of the partial paradigmatic table for ÈTOT given in Table 14 (i). We find, again, that a form (here, ètogo) may cover a smaller or a larger domain (genitive and accusative vs. genitive only) in different subdomains (animate vs. inanimate). Assume, for the sake of the argument, that we had available a reasonable characterization of "genitive-plus-accusative" in terms of underspecification, that is, a uniform categorial specification that covers both genitive and accusative. ${ }^{75}$ We still could not subsume the genitive-accusative reading and the genitive-only reading of ètogo under one uniform categorization. What is different here is that this time the more restricted reading (genitive) is not brought about by intervention of some other ending that carries a more specific categorization (which would have to make its appearance in the inanimate accusative). It would not help to assume that ètot is the more specific form: We could not get a uniform characterization of this form, since no form that is more specific would be available to oust ètot from the animate accusative. Unless some extra mechanism (like referral) is invoked, no uniform categorizations for both ètot and ètogo can be given, provided the constella-

\footnotetext{
${ }^{74}$ See Baerman (2003, sec. 2) for an analysis of this constellation as found with Russian nouns of dec. IA and for general discussion.

${ }^{75}$ Disregarding questions of adequacy, a number of technical complications would have to be overcome; note, for instance, that forms figuring as genitive-accusatives may occur in the prepositional as well (since forms covering the genitive plural are, in non-noun paradigms, in fact plain oblique forms); cf. sec. 2.8, supra.
} 
tion of forms and categories is as displayed in Table 14; at least one of these forms would have to be construed as ambiguous.

A completely analogous situation is found with noun endings; see Table 14 (ii) for forms of the masculine nouns STOL ('table'), inanimate, and SLON ('elephant'), animate. Of course, one might adopt an analysis that resolves syncretisms inside noun paradigms by assigning unique categorizations to the forms in question. ${ }^{76}$ But then for each case of animate genitive-accusative syncretism that is resolved intra-paradigmatically we would get in return an additional pair of "homonymous endings" (as $-a$ in stola, genitive, vs. - $a$ in slona, genitive-accusative). This is true of the genitive singular endings $-a$ and -ovo, of plain oblique plural endings (-ix and - $a x$ ), and of genitive plural endings ( $-o v$ and $-e j$ ); similarly, for genitive plural forms without endings. Plainly, genitive-accusative-syncretism is not bound to certain endings at all; any material that shows up in genitive forms may be subjected to accusativegenitive referral if triggered by animacy. ${ }^{77}$ This situation contrasts starkly with cases of syncretisms that are appropriately accounted for in terms of underspecification.

Consequently, the inventory of ending-categorization pairs should not be extended in order to account for animate genitive-accusatives on an itemby-item basis. After all, there are no endings exclusively for the animate accusative or any other one-of-a-kind animate endings. At the same time, there is no obstacle to amending underspecified paradigms by adding animate accusative forms. In fact, such an emendation may be called for if it is required

\footnotetext{
${ }^{76} \mathrm{Cf}$. Comrie (1986), who proposes a feature [direct] that covers nominative and accusative, and a feature [objective] that covers accusative and genitive, in addition to [genitive] and [nominative] that cover the cases that lend them their names. Non-oblique singular forms of the nouns STOL and SLON are characterized as follows:

stol [direct] slon [nominative]

stola [genitive] slona [objective]

Accepting this analysis as it stands, we would even lose the unified treatment of unmarked base forms. Treatments of genitive-accusative syncretism in Russian using underspecification have also been suggested by Franks (1995, sec. 2.2.2, with some reservations, p. 59, note 44) and Wunderlich (1996, 107), among others; cf. also Gunkel (2003) on Polish.

${ }^{77}$ Fraser \& Corbett (1995, sec. 4). As Corbett has emphasized in various publications, "the type of syncretism found with the animacy features is always the same in Russian (it is always accusative-genitive syncretism)" (Corbett $(1991,167))$ which precludes accepting any approach that "would allow agreements for animate masculines to be completely different from other animates, whereas in all examples it is syncretism of accusative and genitive agreeing forms which is involved." (loc. cit.)
} 
that underspecified paradigms output full arrays of categorized forms as they stand (without recourse to some extra mechanism, such as categorial equations). Since it is derivable that the animate accusative forms of ÈTOT are ètogo (singular) and ètix (plural), we may very well add the following elements to Ѐтот ${ }^{\mathrm{UP}}$ : $\langle$ ètogo, $\{$ acc, sg, masc, anim $\}\rangle,\langle\grave{e} t i x,\{$ acc, $\mathrm{pl}$, anim $\}\rangle$. Similarly, we may take it that SLON ${ }^{\mathrm{UP}}$ contains the derived elements $\langle$ slona, $\{$ acc, sg $\}\rangle,\langle$ slonov, $\{$ acc, $\mathrm{pl}\}\rangle$ besides $\langle$ slona, $\{$ gen, sg $\}\rangle,\langle$ slonov, $\{$ gen, $\mathrm{pl}\}\rangle$, in which case SLON ${ }^{\mathrm{UP}}$ has two more elements than $\mathrm{STOL}^{\mathrm{UP}}$.

In conclusion, the following points should be kept in mind when assessing approaches to the animate accusative-genitive in Russian:

First, Russian animate genitive-accusatives are but one instance of the widely spread phenomenon of differential object marking, intertwined as it often is with syncretism between a marked core case (accusative in an "accusative language" like Russian) and an oblique case, which need not be the genitive.

Second, the non-oblique/oblique dividing line (which is crossed by genitive-accusatives) represents a major factor in determining the structure of Russian case paradigms - and these are not exceptional from a typological point of view - which should have repercussions in the overall structure to be assumed for the Russian case system. ${ }^{78}$

Third, syncretism between genitives and animate accusatives is a uniform phenomenon encompassing singular and plural subparadigms, encompassing different declensions (in the plural), and encompassing different wordclasses, applying as it does to nouns and non-nouns in the presence of the category animate.

\section{Conclusion}

In the preceding analysis of Russian declension, focus has been on aspects of morphological form, especially questions of homonymy and synonymy of morphological markers. In many earlier approaches, syncretisms are dealt

\footnotetext{
${ }^{78}$ The non-obl/obl distinction is also reflected in alternations of word stress and in stem alternations which in most cases support the fourfold division of paradigms generated by this divison as it combines with the sg/pl distinction; cf. Stankiewicz (1968, 66, passim), Johnston (1997). Moreover, there are paradigms with a minimal differentiation of cases, and these show the non-obl/obl distinction, thus the topmost case classification, only; paradigms of this type are found with numerals like SOROK ('forty') (not discussed in this paper); see Garde (1980, $239, \S 370)$.
} 
with in terms of a combinatorial system of syntactic or semantic features; in contrast, the present investigation has been based on a detailed inspection of formal markers, endings in particular, as they are made use of in order to distinguish word forms of paradigms. As a result, a limited inventory of pairs of inflectional endings (or rather form categories determined by reference to endings) and categorizations has been established (Table 10), including specifications of applicability in terms of declension classes. Complemented by a treatment of animate accusatives, this inventory provides a sufficient basis for deriving the standard declensional paradigms of Russian, while its cardinality is small as compared to the number of cells in fully specified paradigms. In a considerable number of instances, seeming ambiguities, often multiple, of endings have given way to the recognition of functional unity, because syncretisms have been taken into account systematically.

Our view on Russian declension has now changed a little. The relation between form and function has become more transparent. Iconicity seems to be involved, and many endings turn out to have unique functions. The contrast between flexive and agglutinative strategies of morphological marking, with which we started, seems to have been mitigated to some degree. Still, Russian has not turned into an agglutinative language: The actual domains of application of declensional markers in Russian are not determined on a stand-alone basis but are controlled by the interplay between forms in paradigms. Some homonymies remain, and their status would have to be examined; only one case in point can be mentioned here. Disregarding the genitive II, which has often been said to be dying out, there are two endings that are used twice in the singular, namely, the nominative and accusative endings, $-a$ and $-u$, respectively, which also distinguish genitive and dative. True, these endings are employed for two purposes; however, in the non-oblique cases they are restricted to feminine nouns, whereas in the oblique cases they are restricted to non-feminine nouns. What matters is that the system as a whole is organized in a way that avoids too much homonymy between word forms, on this point at least. The regulation of genitive plural marking (by the No-Homonymy Condition) as well as the phenomenon of differential object marking would seem to point in the same direction. ${ }^{79}$ While there is no need to accept long series of remaining "homonymous endings", unambiguous markers are not

\footnotetext{
${ }^{79}$ Cf. Comrie (1978, sec. 3); and, for a general discussion of the rôle of morphological exponents in paradigms, see Blevins (this volume).
} 
required either. In a system such as Russian declension, discrimination of forms is what morphological markers are for.

\section{References}

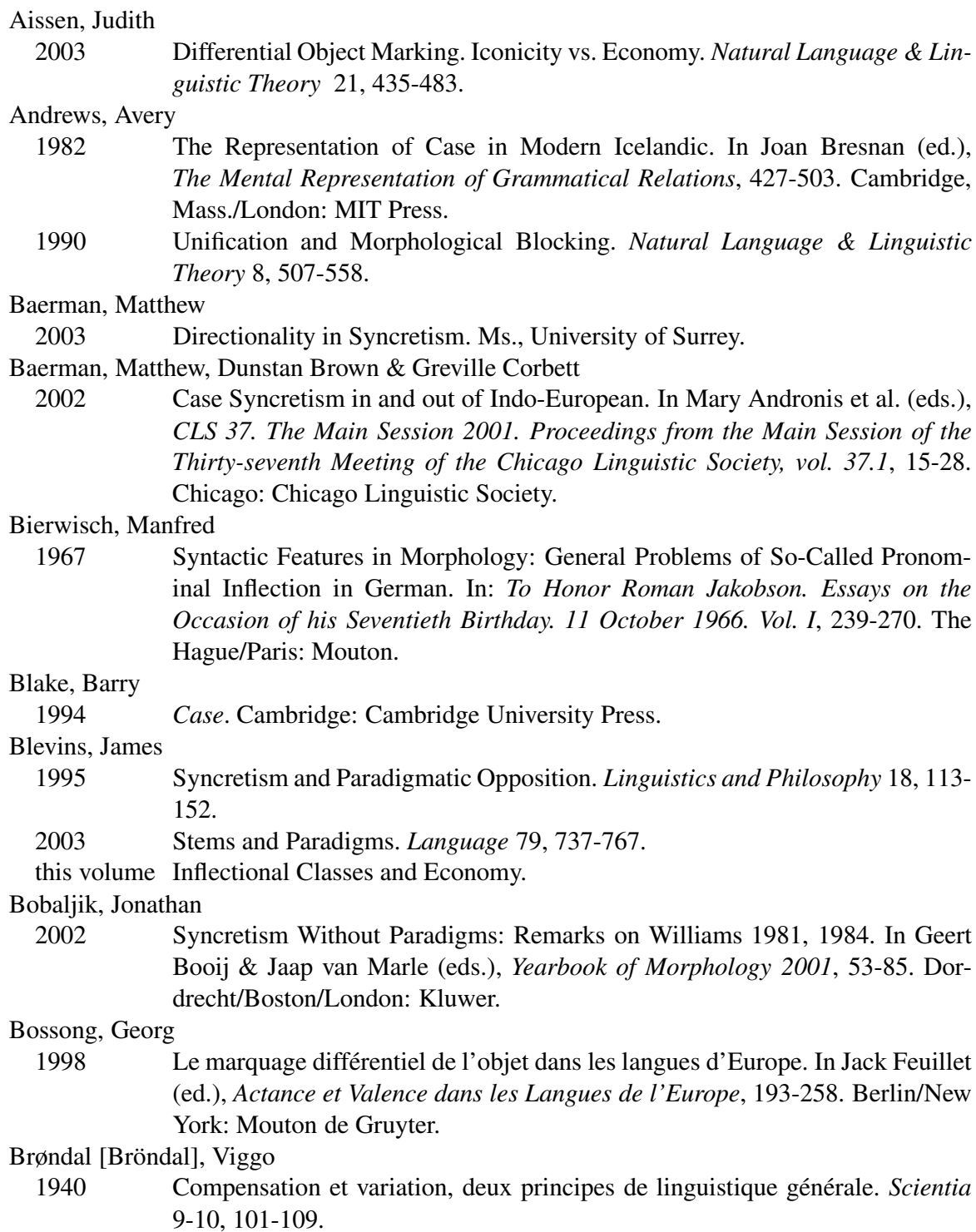

1967 Syntactic Features in Morphology: General Problems of So-Called Pronominal Inflection in German. In: To Honor Roman Jakobson. Essays on the Occasion of his Seventieth Birthday. 11 October 1966. Vol. I, 239-270. The Hague/Paris: Mouton.

Blake, Barry

$1994 \quad$ Case. Cambridge: Cambridge University Press.

Blevins, James

1995 Syncretism and Paradigmatic Opposition. Linguistics and Philosophy 18, 113152.

2003 Stems and Paradigms. Language 79, 737-767.

this volume Inflectional Classes and Economy.

Bobaljik, Jonathan

2002 Syncretism Without Paradigms: Remarks on Williams 1981, 1984. In Geert Booij \& Jaap van Marle (eds.), Yearbook of Morphology 2001, 53-85. Dordrecht/Boston/London: Kluwer.

Bossong, Georg

1998 Le marquage différentiel de l'objet dans les langues d'Europe. In Jack Feuillet (ed.), Actance et Valence dans les Langues de l'Europe, 193-258. Berlin/New York: Mouton de Gruyter.

Brøndal [Bröndal], Viggo

1940 Compensation et variation, deux principes de linguistique générale. Scientia 9-10, 101-109. 
Chvany, Catherine

1982 Hierarchies in the Russian Case System: For N-A-G-P-D-I, against N-G-DA-I-P. Russian Language Journal 36, No. 125, 133-147.

Comrie, Bernard

1978 Genitive-Accusatives in Slavic: The Rules and Their Motivation. In: Bernard Comrie (ed.), Classification of Grammatical Categories, 27-42. Urbana/Edmonton: Linguistic Research.

$1981 \quad$ Language Universals and Linguistic Typology. Oxford: Blackwell.

1986 On Delimiting Cases. In Richard Brecht \& James Levine (eds.), Case in Slavic, 86-106. Columbus, OH: Slavica.

1991 Form and Function in Identifying Cases. In Frans Plank (ed.), Paradigms. The Economy of Inflection, 41-55. Berlin/New York: Mouton de Gruyter.

Comrie, Bernard, Gerald Stone \& Maria Polinsky

1996 The Russian Language in the Twentieth Century. 2nd, rev. \& exp. ed. Oxford: Clarendon.

Corbett, Greville

1980 Animacy in Russian and Other Slavonic Languages: Where Syntax and Semantics Fail to Match. In Catherine Chvany \& Richard Brecht (eds.), Morphosyntax in Slavic, 43-61. Columbus, OH: Slavica.

1981 Syntactic Features. Journal of Linguistics 17, 55-76.

1982 Gender in Russian: An Account of Gender Specification and Its Relationship to Declension. Russian Linguistics 6, 196-232.

1991 Gender. Cambridge: Cambridge University Press.

Corbett, Greville \& Norman Fraser

1993 Network Morphology: A DATR Account of Russian Nominal Inflection. Journal of Linguistics 29, 113-142.

Cubberley, Paul

2002 Russian. A Linguistic Introduction. Cambridge: Cambridge University Press.

Franks, Steven

1995 Parameters of Slavic Morphosyntax. New York/Oxford: Oxford University Press.

Fraser, Norman \& Greville Corbett

1995 Gender, Animacy, and Declensional Class Assignment: A Unified Account for Russsian. In Geert Booij \& Jaap van Marle (eds.), Yearbook of Morphology 1994, 123-150. Dordrecht/Boston/London: Kluwer.

Garde, Paul

1980 Grammaire russe. Tome premier: Phonologie - Morphologie. Paris: Institut d'Études Slaves.

Greenberg, Joseph

1966 Language Universals. In Thomas A. Sebeok (ed.), Current Trends in Linguistics. Vol. 3, Theoretical Foundations, 61-112. The Hague: Mouton.

Gunkel, Lutz

2003 Syncretisms and Case Underspecification in Polish Noun Paradigms. In Piotr Bański \& Adam Przepiórkowski (eds.), Generative Linguistics in Poland: Morphosyntactic Investigations (Proceedings of the GLiP-5 Conference held 
in Warsaw, Poland, 30 November - 1 December 2002), 47-62. Warsaw: Inst. Podstaw Informatyki PAN.

Halle, Morris

1994 The Russian Declension. In Jennifer Cole \& Charles Kisseberth (eds.), Perspectives in Phonology, 321-353. Stanford: CSLI.

Halle, Morris \& Alec Marantz

1993 Distributed Morphology and the Pieces of Inflection. In Kenneth Hale \& Samuel Jay Keyser (eds.), The View from Building 20. Essays in Linguistics in Honor of Sylvain Bromberger, 111-176. Cambridge, Mass./London: MIT Press.

Halle, Morris \& Ora Matushansky

2003 The Morpho-Phonology of Adjectival Inflection in Russian. [Handout]. Cambridge, Mass.: MIT, October 9, 2003.

Hentschel, Gerd \& Thomas Menzel

2002 Marker Productivity, Structural Preferences and Frequency: Observations about Morphological Change in Slavonic Languages. Indogermanische Forschungen 107, 1-46.

Hjelmslev, Louis

1956 Animé et inanimé, personnel et non-personnel. Travaux de l'Institut de Linguistique 1, 155-199.

Isačenko, Aleksandr

1962 Die russische Sprache der Gegenwart. Teil I: Formenlehre. Halle/Saale: Niemeyer.

Jakobson, Roman

1936 Beitrag zur allgemeinen Kasuslehre. Gesamtbedeutungen der russischen Kasus. Travaux du Cercle Linguistique de Prague 6, 240-288. [Repr. in Jakobson (1971), engl. trans. in Jakobson (1984)]

1939 Signe Zéro. In: Mélanges de linguistique offerts à Charles Bally, 143-152. Génève: Georg. [Repr. in Jakobson (1971), engl. trans. in Jakobson (1984)]

1957 The Relationship between Genitive and Plural in the Declension of Russian Nouns. Scando-Slavica 3, 181-186. [Repr. in Jakobson (1971) and (1984)]

1958 Morfologičeskie nabljudenija nad slavjanskim skloneniem (Sostav russkix padežnyx form) [Morphological observations on Slavic declension (The structure of Russian case forms)]. In: American Contributions to the Fourth International Congress of Slavicists, Moscow, September 1958, 127-156. 'sGravenhage: Mouton. (= Slavistic Printings and Reprintings. 21) [Repr. in Jakobson (1971), engl. trans. in Jakobson (1984).]

1960 The Gender Pattern of Russian. Studii şi cercetări lingvistice 11, 3, 541-543. [Repr. in Jakobson (1971) and (1984)]

1965 Quest for the Essence of Language. Diogenes 51, 21-37. [Repr. in Jakobson (1971)]

1971 Selected Writings. Vol. II: Word and Language. The Hague/Paris: Mouton.

1984 Russian and Slavic Grammar. Studies 1931-1981. Ed. by Linda R. Waugh and Morris Halle. Berlin/New York/Amsterdam: Mouton.

Johnston, Jason

1997 Systematic Homonymy and the Structure of Morphological Categories: Some 
Lessons from Paradigm Geometry. Doctoral dissertation, University of Sydney.

Kiparsky, Paul

1972 Explanation in Phonology. In Stanley Peters (ed.), Goals of Linguistic Theory, 189-227. Englewood Cliffs, NJ: Prentice-Hall.

1973 "Elsewhere" in Phonology. In Stephen R. Anderson and Paul Kiparsky (eds.), A Festschrift for Morris Halle, 93-106. New York: Holt, Rinehart and Winston.

Kortlandt, Frederik

1974 Russian Nominal Flexion. Linguistics 130, 55-70.

Lieb, Hans-Heinrich

1980 Words as Syntactic Paradigms. In Gunter Brettschneider \& Christian Lehmann (eds.), Wege zur Universalienforschung. Sprachwissenschaftliche Beiträge zum 60. Geburtstag von Hansjakob Seiler, 115-123. Tübingen: Narr.

1992 Paradigma und Klassifikation: Explikation des Paradigmenbegriffs. Zeitschrift für Sprachwissenschaft 11, 3-46.

2003 Notions of Paradigm in Grammar. Ms., FU Berlin. To appear in D. Alan Cruse et al. (eds.), Lexikologie/Lexicology. Ein internationales Handbuch zur Natur und Struktur von Wörtern und Wortschätzen/An International Handbook on the Nature and Structure of Words and Vocabularies. Berlin: de Gruyter.

Lumsden, John

1992 Underspecification in Grammatical and Natural Gender. Linguistic Inquiry 23, 469-486.

Lunt, Horace

2001 Old Church Slavonic Grammar. 7., rev. ed. Berlin/New York: Mouton de Gruyter.

Lyons, John

1968 Introduction to Theoretical Linguistics. Cambridge: Cambridge University Press.

Matthews, Peter

1991 Morphology. Second Edition. Cambridge: Cambridge University Press.

McCreight, Katherine \& Catherine Chvany

1991 Geometric Representation of Paradigms in a Modular Theory of Grammar. In Frans Plank (ed.), Paradigms. The Economy of Inflection, 91-112. Berlin/New York: Mouton de Gruyter.

Mulisch, Herbert et al.

1988 Russische Sprache der Gegenwart. Vol. 2, Morphologie. Rev. ed. Leipzig: Enzyklopädie.

Müller, Gereon

this volume On Decomposing Inflection Class Features: Syncretism in Russian Noun Inflection.

Paul, Hermann

1919 Deutsche Grammatik. Vol. III, Teil IV: Syntax (Erste Hälfte). Halle: Niemeyer. 
Perlmutter, David \& Janez Orešnik

1973 Language-Particular Rules and Explanation in Syntax. In Stephen R. Anderson and Paul Kiparsky (eds.), A Festschrift for Morris Halle, 419-459. New York: Holt, Rinehart and Winston.

Plank, Frans

1979 Ikonisierung und De-Ikonisierung als Prinzipien des Sprachwandels. Sprachwissenschaft 4, 121-158.

1991 Of Abundance and Scantiness in Inflection: A Typological Prelude. In Frans Plank (ed.), Paradigms. The Economy of Inflection, 1-39. Berlin/New York: Mouton de Gruyter.

1999 Split Morphology: How Agglutination and Flexion Mix. Linguistic Typology 3, 279-340.

Schenker, Alexander

1964 Polish Declension. A Descriptive Analysis. The Hague/London/Paris: Mouton. Shapiro, Michael

1969 Aspects of Russian Morphology. A Semiotic Investigation. Cambridge, Mass.: Slavica.

1971 The Genitive Plural Desinences of the Russian Substantive. The Slavic and

Stankiewicz, Edward East European Journal 15, 190-198.

1968 Declension and Gradation of Russian Substantives in Contemporary Standard Russian. The Hague/Paris: Mouton.

Stump, Gregory T.

1993 On Rules of Referral. Language 69, 449-479.

2001 Inflectional Morphology. A Theory of Paradigm Structure. Cambridge: Cambridge University Press.

2002 Morphological and Syntactic Paradigms. Arguments for a Theory of Paradigm Linkage. In Geert Booij \& Jaap van Marle (eds.), Yearbook of Morphology 2001, 147-180. Dordrecht/Boston/London: Kluwer.

Suppes, Patrick

1972 Axiomatic Set Theory. Corr. ed. New York: Dover.

Thomson, Alexander

1909/1912 Beiträge zur Kasuslehre. I. Über den Genitiv-Akkusativ im Slavischen. IV. Über die Neubildungen des Akkusativs. Indogermanische Forschungen 24, 293-307; 30, 65-79.

Timberlake, Alan

2004 A Reference Grammar of Russian. Cambridge: Cambridge University Press.

Trager, George

1953 Russian Declensional Morphemes. Language 29, 326-338.

Trubetzkoy, Nikolaj S.

1934 Das morphonologische System der russischen Sprache. Prague/Leipzig: Jedn. ceskosl. mat. a fys./Harrassowitz. (= Travaux du Cercle Linguistique de Prague. 5, 2)

Unbegaun, Boris

1957 Russian Grammar. Oxford: Clarendon Press. 
Wade, Terence

1992 A Comprehensive Russian Grammar. Oxford/Malden, Mass.: Blackwell.

Warburton, Irene P.

1973 Modern Greek Verb Conjugation: Inflectional Morphology in a Transformational Grammar. Lingua 32, 193-226.

Wiese, Bernd

1991/1999 Unterspezifizierte Paradigmen. Form und Funktion in der pronominalen Deklination. Paper read at the Symposium "Funktionale Untersuchungen zur deutschen Nominal- und Verbalmorphologie". FAS, Berlin. May 22, 1991. Available via Internet from Linguistik online 3/1999 (http://www.linguistikonline.de/3_99/wiese.html).

1996 Iconicity and Syncretism. On Pronominal Inflection in Modern German. In Robin Sackmann (ed.), Theoretical Linguistics and Grammatical Description. Papers in Honour of Hans-Heinrich Lieb. On the occasion of his 60th birthday, 323-344. Amsterdam/Philadelphia: Benjamins.

2002 Zur lateinischen Nominalflexion. Die Form-Funktions-Beziehung. Paper read at the 26th annual meeting of the Deutsche Gesellschaft für Spachwissenschaft, Mannheim, February 2002. Ms., IDS Mannheim.

Williams, Edwin

1981 On the Notions "Lexically related" and "Head of a Word". Linguistic Inquiry $12,245-274$.

1994 Remarks on Lexical Knowledge. Lingua 92, 7-34.

Wunderlich, Dieter

1996 Minimalist Morphology: The Role of Paradigms. In Geert Booij \& Jaap van Marle (eds.), Yearbook of Morphology 1995, 93-114. Dordrecht/Boston/London: Kluwer.

Wurzel, Wolfgang U.

1989 Inflectional Class Markedness. In Olga Tomić (ed.), Markedness in Synchrony and Diachrony, 227-247. Berlin/New York: Mouton de Gruyter.

Zwicky, Arnold

1985 How to Describe Inflection. In Mary Niepokuj et al. (eds.), Proceedings of the Eleventh Annual Meeting of the Berkeley Linguistics Society, February 16-18, 1985, 372-386. Berkeley: Berkeley Linguistics Society.

1990 Inflectional Morphology as a (Sub)Component of Grammar. In Wolfgang Dressler et al. (eds.). Contemporary Morphology, 217-236. Berlin/New York: Mouton de Gruyter. 